NIST Technical Note 2063

\title{
Pool Boiling of R515A, R1234ze(E), and R1233zd(E) on a Reentrant Cavity Surface; Extensive Measurement and Analysis
}

\author{
Mark A. Kedzierski \\ Lingnan Lin
}

This publication is available free of charge from: https://doi.org/10.6028/NIST.TN.2063

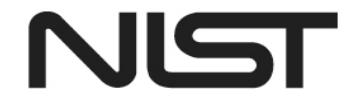

National Institute of Standards and Technology U.S. Department of Commerce 
NIST Technical Note 2063

\title{
Pool Boiling of R515A, R1234ze(E), and R1233zd(E) on a Reentrant Cavity Surface; Extensive Measurement and Analysis
}

\author{
Mark A. Kedzierski \\ Lingnan Lin \\ Energy and Environment Division \\ Engineering Laboratory
}

This publication is available free of charge from:

https://doi.org/10.6028/NIST.TN.2063

September 2019

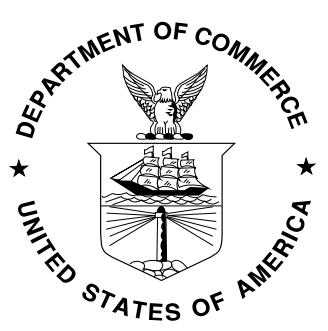

U.S. Department of Commerce Wilbur L. Ross Jr., Secretary

National Institute of Standards and Technology Walter Copan, , NIST Director and Undersecretary of Commerce for Standards and Technology 
Certain commercial entities, equipment, or materials may be identified in this document in order to describe an experimental procedure or concept adequately. Such identification is not intended to imply recommendation or endorsement by the National Institute of Standards and Technology, nor is it intended to imply that the entities, materials, or equipment are necessarily the best available for the purpose.

National Institute of Standards and Technology Technical Note 2063 Natl. Inst. Stand. Technol. Tech. Note 2063, 42 pages (September 2019) CODEN: NTNOEF

This publication is available free of charge from: https://doi.org/10.6028/NIST.TN.2063 


\title{
Pool Boiling of R515A, R1234ze(E), and R1233zd(E) on a Reentrant Cavity Surface; Extensive Measurement and Analysis
}

\author{
M. A. Kedzierski, and L. Lin \\ National Institute of Standards and Technology \\ Gaithersburg, MD 20899
}

\begin{abstract}
This paper quantifies the pool boiling performance of R515A, R1234ze(E), and R1233zd(E) on a flattened, horizontal Turbo-ESP surface for air-conditioning applications for heat fluxes between roughly $10 \mathrm{kWm}^{-2}$ and $100 \mathrm{kWm}^{-2}$. Both R515A and R1234ze(E) are replacements for R134a, while R1233zd(E) is a replacement for R123. The measured boiling curve for R515A had roughly a $14 \%$ larger heat flux than that of R1234ze(E) for heat fluxes greater than $45 \mathrm{kWm}^{-2}$. For heat fluxes between $14 \mathrm{kWm}^{-2}$ and $85 \mathrm{kWm}^{-2}$, R515A and R1234ze(E) exhibited a heat flux that was $33 \%$ and $17 \%$ larger than that for R134a. The heat flux of R1233zd(E) was roughly $18 \%$ larger than that for R123 for heat fluxes between $30 \mathrm{kWm}^{-2}$ and $87 \mathrm{kWm}^{-2}$. A pool boiling model that was previously developed for pure and mixed refrigerants on the Turbo-ESP surface was improved by nondimensionalizing the model constants and improving their statistical significance. For most heat fluxes, the model predicted the measured superheat to within $\pm 0.7 \mathrm{~K}$. The model was used to show that the vapor Prandtl number and the product of the latent heat and vapor density significantly influenced the boiling heat flux.
\end{abstract}

Keywords: boiling, enhanced heat transfer, refrigerants, structured surface 


\section{TABLE OF CONTENTS}

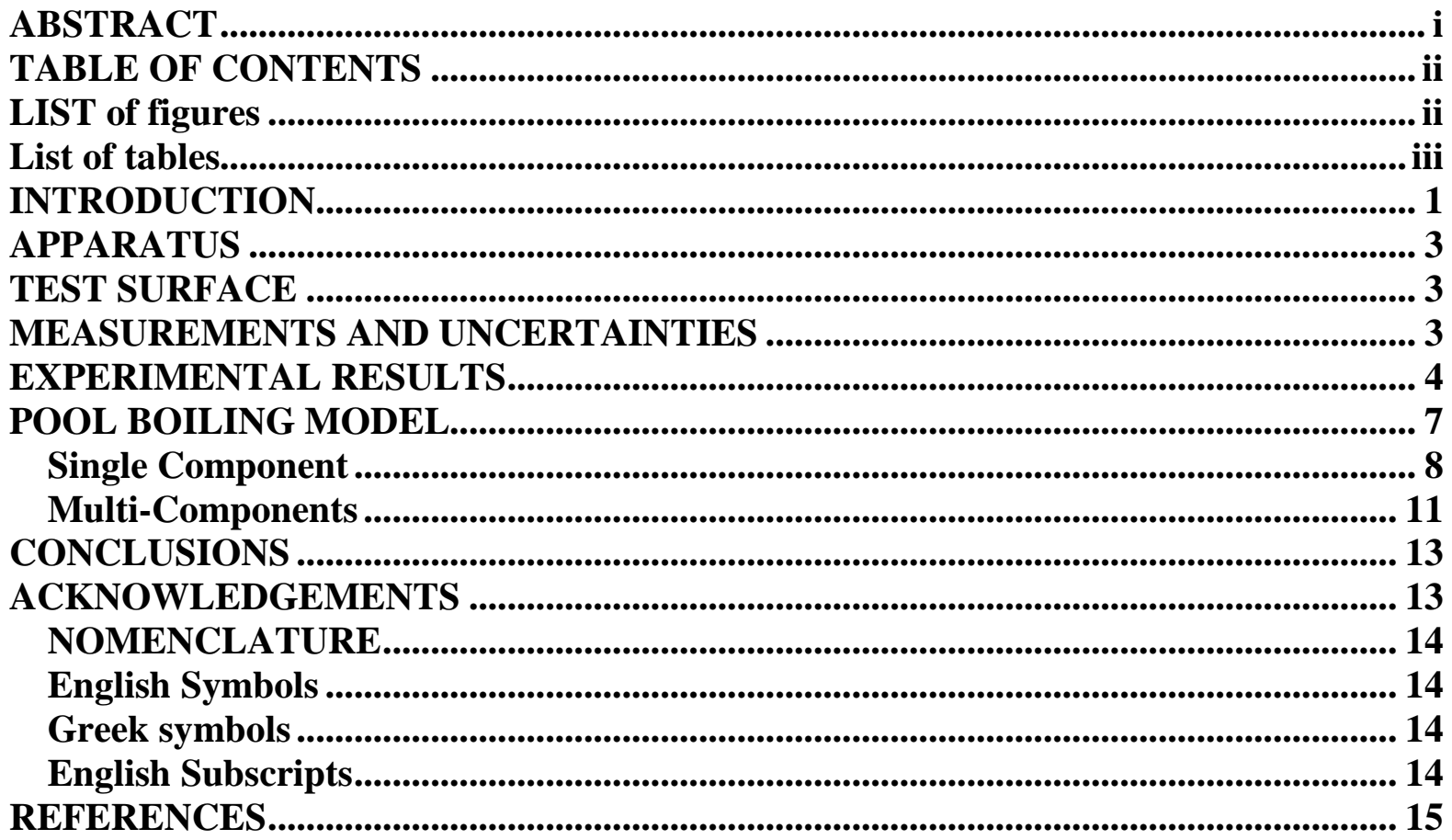

\section{LIST OF FIGURES}

Fig. 1 Schematic of test apparatus

Fig. 2 OFHC copper flat test plate with Turbo-ESP surface and thermocouple coordinate system...

Fig. 3 Photograph of Turbo-ESP surface ......................................................................... 26

Fig. 4 Comparison of boiling curves for R1234ze(E), R515A, and R134a at 277.6 K ... 27

Fig. 5 Comparison of R515A and R1234ze(E) heat fluxes to that for R134a at the same wall superheat

Fig. 6 Comparison of boiling curves for R1233zd(E) and R123 at $277.6 \mathrm{~K}$.................. 29

Fig. 7 Comparison of R1233zd(E) heat fluxes to that for R123 at the same wall superheat.

Fig. 8 Comparison of pool boiling model for Turbo-ESP surface to present measurements for R1234ze(E), R515A, and R1233zd(E).

Fig. 9 Comparison of pool boiling model for Turbo-ESP surface to several refrigerants for several studies..

Fig. 10 Comparison of refrigerant mixture pool boiling model for Turbo-ESP surface to R450A and R513A measurements from Kedzierski et al. (2018) ......................... 33

Fig. 11 Illustration of effect of key properties on pool boiling model heat flux .............. 34 35

Fig. A.1 Expanded relative uncertainty in the heat flux of the surface at the $95 \%$ confidence level.

Fig. A.2 Expanded uncertainty in the temperature of the surface at the $95 \%$ confidence level. 


\section{LIST OF TABLES}

Table 1 Conduction model choice...................................................................................... 18

Table 2 Pool boiling data..................................................................................... 19

Table 3 Number of test days and data points .......................................................... 22

Table 4 Estimated parameters for cubic boiling curve fits ........................................... 22

Table 5 Residual standard deviation of $\Delta T_{\mathrm{s}}$.............................................................. 22

Table 6 Average magnitude of $95 \%$ multi-use confidence interval for mean $\Delta T_{\mathrm{s}} . . . . . . . .23$

Table 7 Selected fluid properties of test refrigerants at saturation (277.6 K) using

REFPROP 10.0 default equations (Lemmon et al., 2018) .................................... 23 


\section{INTRODUCTION}

One of the primary occupations of the air-conditioning and refrigeration industry over the past thirty years has been the search for refrigerants that perform well while not harming the environment. The quest has been difficult because the required characteristics of refrigerants used in cooling equipment are rigorous and numerous. A refrigerant must meet the required temperature, pressure, enthalpy, and heat transfer characteristics while remaining stable and environmentally benign. At first, the Montreal Protocol (1987) set regulations that limited the ozone depletion potential (ODP) of refrigerants. Work toward satisfying zero ODP produced third-generation refrigerants like R123 and R134a. Currently, the industry is in pursuit of fourth-generation refrigerants in order to comply with mandates set by the European F-gas Regulation (EU, 2014) and the Kigali amendment to the Montreal Protocol (UNEP, 2016) that mandate refrigerants with low global warming potential (GWP). These regulations have caused a recent shift to refrigerants with both zero ODP and low GWP. Refrigerant $\mathrm{R} 123$ (ODP $=0.02$ (WMO, 2006)) is a low-pressure refrigerant with a relatively small 100-year horizon GWP ${ }^{1}$ of 79 (Myhre et al., 2013) that has been used chiefly in water chillers that cool large buildings. The new refrigerant R1233zd(E) has the advantage over R123 of having a GWP $<1$ (Myhre et al., 2013). R515A is an azeotrope replacement for R134a, which is a mixture that is $88 \% \mathrm{R} 1233 z d(\mathrm{E})$ and $12 \% \mathrm{R} 227$ ea on a mass basis. The GWPs for R515A and R1234ze(E) are, respectively 403 and $<1$, which both are significantly less than the GWP for R134a, which is 1300 (Myhre et al., 2013).

The commercial application of refrigerant-shell-side enhancements to water chillers began around 1938 with the use of rectangularly finned tubes with rather low fin densities (Rogers,1961). Since then, refrigerant shell-side augmentation has evolved toward more complicated fin shapes and larger fin densities. For example, the "bent fin," introduced in 1971, was a commercial boiling tube that was made specifically for the promotion of reentrant boiling (Kedzierski, 1999). The bent fin tube was created with a simple modification of the rectangularly finned tube by raking the fins back upon themselves producing a specified gap between the fin-tip and the adjacent fin for escaping bubbles, as further explained in US patent 3,696,861 (Webb, 1972). Continued evolution of enhanced boiling tube technology has led to significantly more intricate surfaces than the bent fin. This paper investigates the heat transfer performance of R515A, R1234ze(E), and R1233zd(E) on the Turbo-ESP ${ }^{2}$, which is one of the newer boiling surfaces.

\footnotetext{
${ }^{1}$ All GWP values are given for zero contribution from climate-carbon feedbacks.

${ }^{2}$ Certain trade names and company products are mentioned in the text or identified in an illustration in order to adequately specify the experimental procedure and equipment used. In no case does such an identification imply recommendation or endorsement by the National Institute of Standards and Technology, nor does it imply that the products are necessarily the best available for the purpose.
} 
As expected, considering their recent introduction, relatively few studies involving R515A, R1234ze(E), and R1233zd(E) are in the literature. For example, no heat transfer studies were found in the literature that investigated the performance of R515A. Nagata et al. (2016) measured both condensation and boiling on horizontal smooth tubes for R1234ze(E) and R1233zd(E). They found the measured boiling heat transfer coefficient of R1234ze(E) to be roughly 25 \% larger than that of R134a and 333 \% larger than that of R1233zd(E) at a saturation temperature of $283.15 \mathrm{~K}$. Gorgy (2016) also made pool boiling measurements for R1234ze(E) and R1233zd(E); however, found that the performance of R134a to be similar to that of R1234ze(E). Only three more heat transfer studies were found dealing with R1233zd(E). One was for condensation measurements with R1233zd(E), which was done by Chen (2017) on an enhanced horizontal tube. Another was a flow evaporation measurement study by Lee et al. (2018) that included pressure drop measurements of R1233zd(E) in a brazed plate heat exchanger. The third R1233zd(E) study was for pool boiling measurement on an "enhanced tube 2" that had surface-geometry characteristic that were similar to, but differed, from those of the Turbo-ESP (Byun et al., 2017). Of the three fluids investigated in the present study, most of the previous work has been focused on R1234ze(E). A total of six flow boiling studies and two pool boiling studies were found for R1234ze(E), which includes the Nagata et al. (2016) study above. Considering the R1234ze(E) flow boiling studies, Bortolin et al. (2016) and Bortolin and Del Col (2014) tests were for a single square cross section microchannel; and Kim et al. (2018) measured the performance in various plate heat exchangers with different chevron angles. Grauso et al. (2013) produced a flow pattern map, heat transfer and pressure drop for R1234ze(E) in a horizontal, circular smooth tube. Kim and Cho (2016) measured evaporation heat transfer coefficients for R1234ze(E) in an electrically heated smooth, stainless steel tube. Finally, a pool boiling prediction method for two different enhanced tubes was developed for R134a, R236fa and R1234ze(E) by van Rooyen and Thome (2013).

Of all the above studies, the only boiling measurements that were found in the literature for the Turbo-ESP surface and the refrigerants of the present study were by Gorgy (2016). As stated above, these measurements were for R123, R134a, R1234ze, R1233zd(E), and R450A. The results show that the performance of R1234ze is very similar to that of R134a while R450A shows performance degradation of $28 \%$ compared to R134a. The boiling heat transfer for R1233zd(E) was 19\% greater than that for R123.

Because of the relatively recent introduction of R515A, R1234ze(E), and R1233zd(E), the availability of measured pool boiling heat transfer data presented in the literature for these refrigerants is limited. Consequently, the present study provides pool boiling heat transfer measurements for R515A, R1234ze(E), and R1233zd(E) on the horizontal, flat, copper, Turbo-ESP-finned surface for test conditions that are applicable for air-conditioning applications. 


\section{APPARATUS}

Figure 1 shows a schematic of the apparatus that was used to collect the pool boiling data. More specifically, the apparatus was used to measure the liquid saturation temperature $\left(T_{\mathrm{s}}\right)$, the average pool-boiling heat flux $\left(q^{\prime \prime}\right)$, and the wall temperature $\left(T_{\mathrm{w}}\right)$ of the test surface. The three principal components of the apparatus were a test chamber containing the test surface, the condenser, and the purger. The internal dimensions of the test chamber were $25.4 \mathrm{~mm} \times$ $257 \mathrm{~mm} \times 1.54 \mathrm{~m}$. The test chamber was charged with approximately $7 \mathrm{~kg}$ of refrigerant, giving a liquid height of approximately $80 \mathrm{~mm}$ above the test surface. As shown in Fig. 1, the test section was visible through two opposing, flat $150 \mathrm{~mm} \times 200 \mathrm{~mm}$ quartz windows. The bottom of the test surface was heated with high velocity $(2.5 \mathrm{~m} / \mathrm{s})$ water flow. The vapor produced by liquid boiling on the test surface was condensed by the brine-cooled, shell-andtube condenser and returned as liquid to the pool by gravity. Further details of the test apparatus can be found in Kedzierski (2002) and Kedzierski (2001).

\section{TEST SURFACE}

Figure 2 shows the oxygen-free high-conductivity (OFHC) copper flat test plate used in this study. The test plate was machined out of a single piece of OFHC copper by electric discharge machining (EDM). The internal fins of a commercial $25 \mathrm{~mm}$ (outer-diameter) Turbo-ESP tube were removed by EDM. The tube was then cut axially, annealed, flattened, and soldered onto the top of the test plate. The Turbo-ESP has approximately 1968 fins per meter (fpm) oriented along the short axis of the plate with an approximate fin-thickness of $0.2 \mathrm{~mm}$. Figure 3 shows a photograph of the fin surface and identifies three key geometry parameters: the fin, the gap between fins at the fin-tips, and the slot openings at the fins. The overall fin-height, the gap at the fin-tips, and the width of the fin slots are approximately $0.4 \mathrm{~mm}, 0.04 \mathrm{~mm}$, and $0.05 \mathrm{~mm}$, respectively. The fin-gap and the fin-slots establish the opening size for the exiting bubbles, which is typically sized depending on the surface tension of the boiling fluid. For this reason, the fin-gap and the width of the fin-slot are approximately the same.

\section{MEASUREMENTS AND UNCERTAINTIES}

The standard uncertainty is the square root of the estimated variance. The individual standard uncertainties are combined to obtain the expanded uncertainty $(U)$, which is calculated from the law of propagation of uncertainty with a coverage factor. All measurement uncertainties are reported at the $95 \%$ confidence level except where specified otherwise. Further detail on the heat transfer measurement uncertainties can be found in Appendix A.

All of the copper-constantan thermocouples and the data acquisition system were calibrated against a glass-rod standard platinum resistance thermometer (SPRT) and a reference voltage to a residual standard deviation of $0.005 \mathrm{~K}$. The reference voltage enabled the correction of any drift in the voltage measurement over time. Considering the fluctuations in the saturation temperature during the test and the standard uncertainties in the calibration, the expanded uncertainty of the average saturation temperature was no greater than $0.04 \mathrm{~K}$. Consequently, it is estimated that the expanded uncertainty of the temperature measurements was less than $0.1 \mathrm{~K}$. 
Twenty $0.5 \mathrm{~mm}$ diameter thermocouples were force fitted into the wells of the side of the test plate shown in Fig. 2. The heat flux and the wall temperature were obtained by regressing the measured temperature distribution of the block to the governing two-dimensional conduction equation (Laplace equation). In other words, rather than using the boundary conditions to solve for the interior temperatures, the interior temperatures were used to solve for the boundary conditions following a backward stepwise procedure given in Kedzierski $(1995)^{3}$. As shown in Fig. 2, the origin of the coordinate system was centered on the surface with respect to the y-direction at the heat transfer surface. Centering the origin in the ydirection reduced the uncertainty of the wall heat flux and temperature calculations by reducing the number of fitted constants involved in these calculations.

Fourier's law and the fitted constants from the Laplace equation were used to calculate the average heat flux $\left(q^{\prime \prime}\right)$ normal to and evaluated at the heat transfer surface based on its projected area. The average wall temperature $\left(T_{\mathrm{w}}\right)$ was calculated by integrating the local wall temperature $(T)$. The wall superheat was calculated from $T_{\mathrm{w}}$ and the measured temperature of the saturated liquid $\left(T_{\mathrm{s}}\right)$. Considering this, the relative expanded uncertainty in the heat flux $\left(U_{q^{\prime \prime}}\right)$ was greatest at the lowest heat fluxes, approaching $9 \%$ of the measurement near $15 \mathrm{kWm}^{-2}$. In general, the $U_{q \text { " }}$ remained between $3 \%$ and $6.5 \%$ for heat fluxes greater than $20 \mathrm{kWm}^{-2}$. The average random error in the wall superheat $\left(U_{\mathrm{Tw}}\right)$ remained mainly between $0.06 \mathrm{~K}$ and $0.1 \mathrm{~K}$ with an average value of approximately $0.085 \mathrm{~K}$. The measured thickness of the solder layer, which was used to attach the flattened tube to the copper plate, was less than $0.1 \mathrm{~mm}$ and was accounted for when calculating the measurements and the uncertainties following procedures as outlined in Kedzierski (1995). Plots of $U_{q \text { " }}$ and $U_{\mathrm{Tw}}$ versus heat flux can be found in Appendix A.

\section{EXPERIMENTAL RESULTS}

All pool-boiling measurements were made at a saturated temperature of 277.6. The heat flux was varied between $10 \mathrm{kWm}^{-2}$ and $100 \mathrm{kWm}^{-2}$ to simulate a range of possible operating conditions for R123 and R134a chillers. The data were recorded consecutively starting at the largest heat flux and descending in intervals of approximately $4 \mathrm{kWm}^{-2}$. The descending heat flux procedure minimized the possibility of observing any hysteresis effects on the data, which would have made the data sensitive to the initial operating conditions. Check out tests with R134a were done prior to each new study to ensure that the present boiling performance closely repeated previous measurements with R134a. Table 2 presents the measured heat flux and wall superheat for all the data of this study. Table 3 gives the number of test days and data points for each fluid. A total of 466 measurements were made over 19 days.

Figure 4 is a plot of the measured boiling heat flux $(q ")$ versus the measured wall superheat $\left(T_{\mathrm{W}}-T_{\mathrm{s}}=\Delta T_{\mathrm{s}}\right)$ for R1234ze(E) and R515A on the Turbo-ESP at a saturation temperature of 277.6 K. The open circles and open squares represent the measured data for R1234ze(E) and R515A, respectively. The solid line is a cubic best-fit regression or estimated mean of the data. Seven test days with R1234ze(E) produced 145 measurements over a period of six days. Four of the 145 measurements were removed before fitting because they were

\footnotetext{
${ }^{3}$ Table 1 provides functional forms of the Laplace equation that were used in this study in the same way as was done in Kedzierski (1995) and in similar studies by this author.
} 
statistically identified as "outliers” based on having both high influence and high leverage (Belsley et al., 1980). The data sets for each test fluid presented in this manuscript exhibited a similar number of outliers and were regressed in the same manner. Surface aging data (i.e., "break-in" data) also were not included in the analyzed data sets. The surface aging data typically occurred for each fluid over the first or first and second test days and deviated significantly from the mean of the succeeding and consecutive measurements made over six to seven days. Surface aging was not observed over the included data because the betweenrun variation was approximately random.

Table 4 gives the constants for the cubic regression of the superheat versus the heat flux for all of the fluids tested here and the superheat range for which each regression is valid. The residual standard deviation of the regressions - representing the proximity of the data to the mean - are given in Table 5 and are, on average, approximately $0.05 \mathrm{~K}$. The dashed lines to either side of the mean boiling curve (solid line), in Figs. 4 and 6, represent the lower and upper $95 \%$ simultaneous (multiple-use) confidence intervals for the mean and are, for much of the data, concealed by the data symbols. From the confidence intervals, the expanded uncertainty of the estimated mean wall superheat was, on average, $0.03 \mathrm{~K}$. Table 6 provides the average magnitude of the $95 \%$ multi-use confidence interval for the fitted wall superheat for all of the test data. Table 7 provides selective fluid properties for the test refrigerants evaluated with REFPROP 10.0 (Lemmon, et al., 2018) at a saturation temperature of $277.6 \mathrm{~K}$.

Figure 4 compares pool-boiling measurements of R1234ze(E) and R515A to those of Gorgy (2016), Kedzierski et al. (2018), and Kedzierski and Lin (2018) for R134a on the Turbo-ESP surface at a saturation temperature of $277.6 \mathrm{~K}$. In general, the boiling performance of R1234ze(E) and R515A are both better than that of R134a, and the boiling performance of R515A is better than that of R1234ze(E). For heat fluxes larger than $30 \mathrm{kWm}^{-2}$, the boiling heat flux is roughly $17 \%$ larger than that of R1234ze(E) at the same superheat. The Gorgy (2016) R134a measurements are represented by a long-dashed black line. The line was produced by using a correlated fit that was provided in Gorgy (2016) and the heat flux was adjusted so that it was evaluated at the base of the fins rather than at the fin-tips. The Gorgy (2016) measurements were obtained by means of a Wilson (1915) plot for a test section consisting of three $914 \mathrm{~mm}$ long, water cooled tubes in a $245 \mathrm{~mm}$ diameter shell. For the same wall superheat, the Gorgy (2016) heat flux for R134a is on average approximately $17 \%$ less than the heat flux measured by Kedzierski et al. (2018) and Kedzierski and Lin (2018) for R134a. By comparison, the R1234ze(E) Gorgy (2016) heat flux measurements on a tube were, on average, $30 \%$ less than the present measurement for R1234ze(E) on a plate at the same superheat. Some of these measurement differences may be attributed to manufacturing tolerances between the test surfaces; a round tube versus a flat test section; the effect of averaging heat fluxes over different test section lengths; and an indirect versus a direct measurement method. In general, the boiling heat transfer performance of a flattened enhanced tube compares closely to that of a single round tube of the same enhancement (e.g., Kedzierski, 1995 and Kedzierski et al., 2018). This is because the fin canopy effectively isolates the bubble nucleation from the fluid convection that occurs above the fins, which can be the main physical difference in ebullition between a flat plate and a round tube. 
Figure 5 shows a more precise illustration of the boiling heat transfer rate of R1234ze(E) and R515A relative to Rl34a that is given in Fig. 4. Figure 5 plots the ratio of the R1234ze(E) heat flux and the R515A heat flux to the R134a heat flux from Kedzierski and Lin (2018) at the same wall superheat. The heat flux ratio is shown as a solid line with dashed lines representing the $95 \%$ multi-use confidence level for each mean. A heat transfer difference is confirmed where the $95 \%$ simultaneous confidence intervals (depicted by the dashed lines) do not include the value one. The maximum heat flux ratios for R1234ze(E) and R515A nearly coincide at about 1.81 for a R134a heat flux of approximately $14 \mathrm{kWm}^{-2}$. The heat flux ratios for both fluids decrease with respect to increasing R134a heat flux. The minimum heat flux ratio for both fluids was observed at approximately $85 \mathrm{kWm}^{-2}$ where the ratio for R515A and R1234ze(E) was $1.14 \pm 0.01$ and $1.03 \pm 0.01$, respectively. The heat flux ratio, averaged between $14 \mathrm{kWm}^{-2}$ and $85 \mathrm{kWm}^{-2}$, was approximately 1.33 and 1.17 for R515A and R1234ze(E), respectively. For superheats greater than $1 \mathrm{~K}$, the difference between R515A and R1234ze(E) was nearly constant with the heat flux of R515A being, on average, roughly $14 \%$ greater than that of R1234ze(E). As will be discussed in the model development section, it is speculated that the greater boiling heat flux of R515A is due to its smaller vapor Prandtl number as compared to R1234ze(E).

It is apparent from the above discussion that the relative performance of R1234ze(E) and R134a differ for the present study and the Gorgy (2016) study. For the same superheat, the heat flux for R1234ze(E) and R134a are within $5 \%$ of each other for the Gorgy (2016) study and essentially do not differ for heat fluxes less than $36 \mathrm{kWm}^{-2}$. By comparison, the present study shows a more significant heat flux difference between R1234ze(E) and R134a, with the heat flux of R1234ze(E) being, on average, $17 \%$ larger than that of R134a. Part of the reason for this difference, is that the Wilson (1915) Plot used by Gorgy (2016) requires an assumption for the form of the water-side heat transfer coefficient. Gorgy (2016) compared refrigerant-side heat transfer coefficient uncertainty results for three different functional forms for the water-side Nusselt numbers and found them all to be approximately $4 \%$. One criticism of the Gorgy (2016) experimental design is that the heat transfer resistances of the water-side and the refrigerant-side were roughly equal. An accurate Wilson (2016) Plot requires that the water-side heat transfer resistance be significantly smaller than the heat transfer resistance side that is to be measured so that the error contributed by the water-side resistance is minimized. As a result of the balanced resistances, when two of the Wilson (1915) Plot derived water-side Nusselt numbers for the Gorgy (2016) study are used in the overall conductance equation to calculate refrigerant-side heat transfer coefficients they differ, on average, by approximately $25 \%$. In other words, the Gorgy (2016) uncertainty calculation of $4 \%$ for the refrigerant-side heat transfer coefficient is valid only if the assumed water-side model is correct and without bias. Because of this, the uncertainty calculation is likely underestimated because it does not account for bias in the refrigerantside heat transfer coefficient as caused by bias in the assumed water-side model. The negative influence of the water-side model choice would have been mitigated had the waterside heat transfer resistance been significantly smaller. In conclusion, the uncertainty and heat transfer calculations for direct heat transfer measurements, like those presented here, are more reliable than those typically associated with a Wilson (1915) Plot method. 
Figure 6 compares the pool-boiling heat flux $\left(q^{\prime \prime}\right)$ versus the wall superheat $\left(T_{\mathrm{w}}-T_{\mathrm{s}}\right)$ for the Turbo-ESP surface measured in this study for R1233zd(E) and for R123 from Kedzierski and Lin (2018). Comparison of the mean boiling curves shows that the heat flux of R1233zd(E) exceeds that of R123 by approximately $10 \mathrm{kWm}^{-2}$, on average. Figure 6 shows a similar difference for the Gorgy (2016) data where the boiling heat flux of R1233zd(E) is, on average, approximately $10 \mathrm{kWm}^{-2}$ larger than that for R123. Although, the relative performance difference between the two refrigerants is comparable for the two data sets, a significant difference exists between the measured heat flux for the two data sets. For example, the Gorgy (2016) heat flux for R1233zd(E) is, on average, $27 \%$ less than measured for R1233zd(E) in the present study. Likewise, the Gorgy (2016) heat flux for R123 is, on average, 33 \% less than that measured by Kedzierski and Lin (2018). These differences can be attributed to the reasoning provided in the preceding discussion.

For a more detailed comparison, Fig. 7 plots the ratio of the R1233zd(E) heat flux to that of R123 at a saturation temperature of $277.6 \mathrm{~K}$ and at the same wall superheat. As done for Fig. 5 , the heat flux ratio is shown as a solid line with dashed lines representing the $95 \%$ multiuse confidence level for each mean. The largest heat flux ratio occurred at the lowest heat flux, while the smallest heat flux ratio was seen for the highest heat fluxes. The average heat flux ratio for heat fluxes between $9 \mathrm{kWm}^{-2}$ and $30 \mathrm{kWm}^{-2}$ was approximately 1.66. The average flux ratio for R123 for heat fluxes between $30 \mathrm{kWm}^{-2}$ and $87 \mathrm{kWm}^{-2}$ was approximately 1.18. The maximum and minimum heat flux ratios were $2.23 \pm 0.04$ at 9 $\mathrm{kWm}^{-2}$ and $1.07 \pm 0.01$ at $87 \mathrm{kWm}^{-2}$, respectively. The primary reason for $\mathrm{R} 1233 \mathrm{zd}(\mathrm{E})$ having a better boiling performance than R123 is because, as can be calculated from the property data given in Table 7 , the product of the latent heat $\left(h_{\mathrm{fg}}\right)$ and the vapor density $\left(\rho_{\mathrm{v}}\right)$ for R1233zd(E) is roughly $40 \%$ larger than that for R123. As will be shown in the following model development, the ebullition part of the boiling heat flux is proportional to $h_{\mathrm{fg}} \rho_{\mathrm{v}}$.

Nagata et al. (2016) presents boiling measurements on a smooth tube for several of the refrigerants of this study. The ratio of the Turbo-ESP heat transfer coefficient based on the projected area to the heat transfer coefficient of the smooth tube can be obtained by using the present measurements and the Nagata et al. (2016) measurements at the same heat flux. This enhancement ratio is equivalent to the smooth tube wall superheat divided by the Turbo-ESP wall superheat. On average, the enhancement ratio, based on the projected area, was approximately 7, 19, and 25 for R134a, R1233zd(E), and R1234ze(E), respectively.

\section{POOL BOILING MODEL}

The following describes a redevelopment of the pool-boiling model for the Turbo-ESP surface that was presented in Kedzierski et al. (2018). The purpose of the redevelopment was to validate the model for more refrigerants and to increase the statistical significance of the model constants. A total of nine low-GWP refrigerants were included in the model development, including the refrigerants presented in this work and those measurements presented in Kedzierski et al. (2018) and Kedzierski and Lin (2019). The original model includes an adjustment for refrigerant mixtures that had a dimensional constant that is replaced here by one that is non-dimensional. 


\section{Single Component}

As outlined in Kedzierski et al. (2018), the total boiling heat flux is modeled as a sum of the boiling phase-change heat flux $\left(q_{b}^{\prime \prime}\right)$ and the heat flux due to single-phase convection $\left(q_{c}^{\prime \prime}\right)$ :

$$
q^{\prime \prime}=q_{\mathrm{b}}^{\prime \prime}+q_{\mathrm{c}}^{\prime \prime}=n_{\mathrm{b}}\left(h_{\mathrm{fg}} \rho_{\mathrm{v}} V_{\mathrm{b}}+\rho_{\mathrm{l}} c_{\mathrm{pl}} V_{\mathrm{bL}} \Delta T_{\mathrm{s}}\right)
$$

where $n_{\mathrm{b}}$ is the number of bubbles generated per unit time and per unit area. In addition, the properties of the refrigerant are the latent heat of vaporization $\left(h_{\mathrm{fg}}\right)$, the vapor density $\left(\rho_{\mathrm{v}}\right)$, the liquid density $\left(\rho_{\mathrm{l}}\right)$, and the liquid specific heat $\left(c_{\mathrm{pl}}\right)$. The average volume of a single bubble is $V_{\mathrm{b}}$ and the volume of superheated liquid that a single bubble carries away with it into the bulk liquid is $V_{\mathrm{bL}}$. Equation (1) represents an energy balance at the boiling surface. Although the second term represents heat leaving as single phase, the superheated liquid associated with it evaporates into the bubble immediately after being formed. This concept is consistent with that proposed by Mikic and Rohsenow (1969).

The volume of superheated liquid that is carried away from a single bubble is approximated by the product of the bubble surface area and the thickness of the superheated layer $(I)$ that uniformly surrounds the entire bubble surface as:

$$
V_{\mathrm{bL}}=\pi D_{\mathrm{b}}^{2} \Gamma=4.84 V_{\mathrm{b}}^{2 / 3} \Gamma
$$

The Fritz (1935) expression for the bubble diameter $\left(D_{\mathrm{b}}\right)$ is used to obtain a relation for the volume of a single bubble as:

$$
V_{\mathrm{b}}=\frac{\pi}{6} D_{\mathrm{b}}^{3}=\frac{\pi}{6}(0.0208 \theta)^{3}\left(\frac{\sigma}{g\left(\rho_{\mathrm{l}}-\rho_{\mathrm{v}}\right)}\right)^{3 / 2}
$$

The constant group $\pi(0.0208 \theta)^{3} / 6$ will be approximately equal to 0.2 considering that a typical value for the contact angle $\left(\theta\right.$ ) of a refrigerant is $35^{\circ}$ (Kedzierski, 1993). The $g$ is the gravitational acceleration constant.

An expression for the thickness of the superheated layer on the bubble can be derived by starting with the Stokes (1880) expression for the terminal velocity of a bubble rising through a liquid due to buoyance:

$$
u=\frac{\rho\left(\rho_{1}-\rho_{\mathrm{v}}\right) g D_{\mathrm{b}}^{3}}{18 \mu_{1}^{2}}
$$

While using the Fritz (1935) equation for the bubble diameter, the Reynolds number (Re) based on the Stokes (1880) velocity is: 


$$
\operatorname{Re}=\frac{\rho_{1} u D_{\mathrm{b}}}{\mu_{1}}=\frac{c_{0} \rho_{1} \sigma}{3 \pi \mu_{1}^{2}} \sqrt{\frac{\sigma}{\left(\rho_{1}-\rho_{\mathrm{v}}\right) g}}=\frac{0.0214 \rho_{1} \sigma}{\mu_{1}^{2}} \sqrt{\frac{\sigma}{\left(\rho_{1}-\rho_{\mathrm{v}}\right) g}}
$$

Simple dimensionless analysis yields a non-dimensional superheat layer thickness for the bubble as $\Gamma \rho \sigma / \mu^{2}$, which was regressed to the bubble Reynolds number as:

$$
\frac{\Gamma \rho_{1} \sigma}{\mu_{1}^{2}}=0.012 \operatorname{Re}^{1.39}
$$

The leading constant on the Re differs from that presented in Kedzierski et al. (2018) due to the regression containing a larger data set.

Mikic and Rohsenow (1969) showed that the bubble site density is proportional to the wall superheat raised to some power. The $n_{\mathrm{b}}$ can be obtained from a product of the bubble site density and the bubble frequency. Kedzierski (1995) showed that the bubble frequency can be widely variant due to interaction with adjacent sites, but in general, increases with heat flux and wall superheat. Considering the difficulty in modeling the bubble frequency, its functionality with respect to superheat was lumped with that of the active site density in a way that the relationship for $n_{\mathrm{b}}$ is assumed to be (Kedzierski et al., 2018):

$$
n_{\mathrm{b}}=c_{1} \Delta T_{\mathrm{s}}^{\mathrm{m}}
$$

where $c_{1}$ is a constant while the exponent m was proposed in Kedzierski et al. (2018) to be a function of the probability of a site being active, which was assumed to be directly related to the ratio of the thermal boundary layer thickness $(\delta)$ on the boiling surface and the bubble diameter $\left(D_{\mathrm{b}}\right)$ :

$$
\mathrm{m}=\frac{\delta}{D_{\mathrm{b}}}=\beta \sqrt{\frac{\mu_{\mathrm{l}} g\left(\rho_{\mathrm{l}}-\rho_{\mathrm{v}}\right)}{C_{\mathrm{pl}} \sigma}}
$$

In the Kedzierski et al. (2018) analysis, it was required that the constant $\beta$ in eq. (8) was dimensional to ensure that $\mathrm{m}$ was non-dimensional. A new regression of $\mathrm{m}$ to non-dimensional terms that shared the same properties as those in eq. (8), with the exception that the specific heat of vapor $\left(c_{\mathrm{pv}}\right)$ was used rather than $c_{\mathrm{pl}}$, is given in terms of the Re and the vapor Prandtl number $\left(\operatorname{Pr}_{\mathrm{v}}\right)$ as:

$$
\mathrm{m}=\frac{29.3}{\operatorname{Pr}_{\mathrm{v}}^{3} \sqrt{\mathrm{Re}}}
$$

The $\operatorname{Pr}_{v}$ likely represents the ferocity of the boiling where smaller $\operatorname{Pr}_{\mathrm{v}}$ correspond to greater energy diffusion as compared to momentum diffusion, i.e., more bubble nucleation as compared to liquid superheat. The Re relates to the speed of the bubble leaving the surface. Bubbles that quickly leave the surface are not available to interact with other bubbles, coalesce and improve boiling. Consequently, smaller Re and $\operatorname{Pr}_{v}$ both improve boiling. The effect of Re is significantly smaller than that of $\operatorname{Pr}_{\mathrm{v}}$. 
Likewise, the relationship for $n_{\mathrm{b}}$ was improved for the current model as:

$$
n_{\mathrm{b}}=5.23 \times 10^{8}\left(\frac{\sigma}{h_{\mathrm{fg}} \rho_{\mathrm{v}} r_{\mathrm{c}}}\right)^{0.28} \Delta T_{\mathrm{s}}^{\frac{29.3}{\mathrm{Pr}_{\mathrm{v}}^{3} \sqrt{\mathrm{Re}}}}
$$

The property group ratio raised to the 0.28 power is dimensionless and the characteristic surface cavity radius $\left(r_{\mathrm{c}}\right)$ for the Turbo-EPS that was obtained from regression was $2.67 \mu \mathrm{m}$. The expression for the m-expression given in eq. (8) was substituted into eq. (7). Rather than being a constant as for the previous version of the model, the $c_{1}$ is equal to a new constant multiplied by the dimensionless cavity curvature ratio raised to the 0.26 power.

Substitution of eqs. (2), (3) and (9) into eq. (1) yields:

$$
q^{\prime \prime}=5.23 \times 10^{8}\left(\frac{\sigma}{h_{\mathrm{fg}} \rho_{\mathrm{v}} r_{\mathrm{c}}}\right)^{0.28} \Delta T_{\mathrm{s}}^{\frac{29.3}{\mathrm{Pr}_{\mathrm{v}}^{3} \sqrt{\mathrm{Re}}}}\left[h_{\mathrm{fg}} \rho_{\mathrm{v}} \frac{\pi}{6}(0.0208 \theta)^{3}\left(\frac{\sigma}{g\left(\rho_{\mathrm{l}}-\rho_{\mathrm{v}}\right)}\right)^{3 / 2}+4.84\left(\frac{\pi}{6}\right)^{2 / 3}(0.0208 \theta)^{2} \rho_{\mathrm{l}} C_{\mathrm{pl}}\left(\frac{\sigma}{g\left(\rho_{\mathrm{l}}-\rho_{\mathrm{v}}\right)}\right) \Gamma \Delta T_{\mathrm{s}}\right]
$$

Solving eq. (6) for $\Gamma$ and substituting it into eq. (10) and grouping constants gives the complete boiling model for the Turbo-EPS surface:

$$
q^{\prime \prime}=1.06 \times 10^{8}\left(\frac{\sigma}{h_{\mathrm{fg}} \rho_{\mathrm{v}} r_{\mathrm{c}}}\right)^{0.28} \Delta T_{\mathrm{s}}^{\frac{29.3}{\mathrm{Pr}_{\mathrm{v}}^{3} \sqrt{\operatorname{Re}}}}\left[h_{\mathrm{fg}} \rho_{\mathrm{v}}\left(\frac{\sigma}{g\left(\rho_{\mathrm{l}}-\rho_{\mathrm{v}}\right)}\right)^{3 / 2}+0.1 \frac{\mu_{1}^{2} c_{\mathrm{pl}} \operatorname{Re}^{1.39}}{g\left(\rho_{\mathrm{l}}-\rho_{\mathrm{v}}\right)} \Delta T_{\mathrm{s}}\right]
$$

The constants for the above model are dimensionless and were evaluated for a contact angle $(\theta)$ of $35^{\circ}$. In addition, use of an effective cavity radius $\left(r_{\mathrm{c}}\right)$ of $2.67 \mu \mathrm{m}$ is necessary to predict the boiling measurement for the Turbo-ESP surface. Equation (11) could serve as the basis of a boiling model for surfaces other than the Turbo-EPS by adjusting the cavity radius to fit the boiling measurements for a specific surface. If the form of the above model is to be used for other surfaces, it is recommended to fix the contact angle at $35^{\circ}$ and adjust the cavity radius because the cavity radius is raised to a lesser power than the contact angle and affects the boiling and convective terms equally, which causes the model to be less sensitive to variations in $r_{\mathrm{c}}$.

The constants were regressed using the boiling data of seven refrigerants at nine different pressures: R134a and R1234yf (Kedzierski et al., 2018), and R123 and R1336mzz(E) (Kedzierski et al., 2019), and the refrigerants tested here; R515A, R1234ze(E), and R1233zd(E).

Figure 8 compares eq. (11) to the pool boiling measurements for R1234ze(E), R515A, and $\mathrm{R} 1233 z d(\mathrm{E})$. Figure 8 shows that the superheat is predicted to within $\pm 0.3 \mathrm{~K}$ for all three of the fluids. Of the three fluids, the model predicts the boiling heat flux of R1234ze(E) the best 
with an average absolute difference between measurements and predictions of approximately $6 \%$. By comparison, the average absolute difference between measurements and predictions for the R1233zd(E) is roughly $13 \%$ with low heat flux data being overpredicted and high heat flux data being underpredicted. The model predicts the boiling heat flux of R515A to within $17 \%$, on average. Of the nine fluids/conditions that were used to fit the model coefficients, the model predicts the boiling heat flux of R515A with the greatest absolute difference. Table 7 shows that REFPROP 10.0 (Lemmon, et al., 2018) with the volume-translated ${ }^{4}$ PengRobinson (1976) model was used rather than the default REFPROP 10.0 (Lemmon, et al., 2018) equation of state for all R515A properties except for the liquid and vapor densities. This was done because the predictions with the default option significantly increased the deviation from the measurements and no other fluid had comparable deviations while using the default-option properties.

Figure 9 compares the measured heat flux for seven different fluids and three different saturation temperatures to the boiling heat flux predicted with eq. (11). All of the compared measurements were taken on the same test surface and within the same test apparatus. The measurements for R134a and R1234yf were taken from Kedzierski et al. (2018). The measurements for R123 and R1336mzz(Z) at the three different saturation temperatures were taken from Kedzierski and Lin (2019). The comparison shows that $75 \%$ of all the measurements are predicted to within $\pm 20 \%$. By comparison, $90 \%$ and $50 \%$ of the measurements are predicted to within $\pm 20 \%$ for heat fluxes greater than and less than 45 $\mathrm{kWm}^{-2}$, respectively. The reason for this is that the range for the absolute prediction deviation remains relatively constant with respect to heat flux, which becomes a larger percentage at lower heat fluxes. For example, the heat flux of R134a is underpredicted, on average, by a nearly constant $9 \mathrm{kWm}^{-2}$ for heat fluxes less than $45 \mathrm{kWm}^{-2}$, which corresponds increasing percent underpredictions for decreasing heat flux. For all fluids and superheats larger than $1.5 \mathrm{~K}$, the average absolute deviation between measurement and predictions is $8.6 \%$, with R134a having the smallest average prediction deviation (3.6\%) and R1336mzz(Z) at $T_{\mathrm{s}}=$ $298.1 \mathrm{~K}$ having the largest (15.2\%). Considering all the measurements, the average deviation is $15.4 \%$, with R1234ze(E) having the smallest deviation (5.9 \%) and R134a having the largest deviation (19.7\%).

\section{Multi-Components}

The following section presents a modification to a correction multiplier developed by Kedzierski et al. (2018) for the multi-component mixtures R513A and R450A. The correction, when multiplied by eq. (11), provides a boiling heat transfer prediction for R513A and R450A and is general enough to be extended to other mixtures when data becomes available. The multiplier is a product of the heat transfer degradation due to mass transfer resistance and that due to the loss of available superheat (Shock, 1982).

Kedzierski et al. (2018) modeled the heat flux as degraded by the loss of available superheat as ( $\left.q_{\mathrm{g}}^{\prime \prime}\right)$ :

\footnotetext{
${ }^{4}$ The Peng-Robinson (1976) with a constant volume shift.
} 


$$
\frac{q_{\mathrm{g}}^{\prime \prime}}{q^{\prime \prime}}=\left(1-\frac{\Delta T_{\mathrm{g}}}{\Delta T_{\mathrm{s}}}\right)^{\frac{29.3}{\mathrm{Pr}_{\mathrm{v}}^{3} \sqrt{\mathrm{Re}}}}
$$

where the $\Delta T_{\mathrm{g}}$ is the temperature glide, which is the difference between the dew-point temperature $\left(T_{\mathrm{d}}\right)$ and the bubble-point temperature $\left(T_{\mathrm{b}}\right)$. The $\Delta T_{\mathrm{g}}$ is not available for boiling, which causes a boiling degradation because the superheat must surpass $\Delta T_{\mathrm{g}}$ before boiling can occur. Kedzierski et al. (2018) used an exponent (m) that contained a dimensional constant for the expression in eq. (12). As an improvement, the dimensional exponent (m) was replaced with the non-dimensional form of the exponent (m) given in eq. (8).

Kedzierski et al. (2018) estimated the heat flux as degraded by the mass transfer resistance $\left(q_{\mathrm{d}}^{\prime \prime}\right)$ as:

$$
\frac{q_{\mathrm{d}}^{\prime \prime}}{q^{\prime \prime}}=\left(1-\frac{1.24 \Delta T_{\mathrm{g}}}{\Delta T_{\mathrm{s}}^{\frac{29.3}{\mathrm{P}_{\mathrm{v}}^{3} \sqrt{\mathrm{Re}}}}}\right)
$$

Like eq. (12), eq. (13) is an improved version of that given by Kedzierski et al. (2018) in that the previously dimensional exponent on the superheat was replaced with the dimensionless eq. (8) exponent. In addition, the constant on the temperature glide was refitted, which changed it from 1.29 to 1.24 .

By using eqs. (12) and (13) as multiplying factors for eq. (11), the pool boiling heat flux for the Turbo-ESP surface can be modeled for mixtures $\left(q_{\mathrm{m}}^{\prime \prime}\right)$ as:

$$
q_{\mathrm{m}}^{\prime \prime}=1.06 \times 10^{8}\left(\frac{\sigma}{h_{\mathrm{fg}} \rho_{\mathrm{v}} r_{\mathrm{c}}}\right)^{0.28} \Delta T_{\mathrm{s}}^{\frac{29.3}{\mathrm{Pr}_{\mathrm{v}}^{3} \sqrt{\mathrm{Re}}}}\left(1-\frac{1.24 \Delta T_{\mathrm{g}}}{\Delta T_{\mathrm{s}}^{\frac{29.3}{\mathrm{Pr}_{\mathrm{v}}^{3} \sqrt{\mathrm{Re}}}}}\right)\left(1-\frac{\Delta T_{\mathrm{g}}}{\Delta T_{\mathrm{s}}}\right)^{\frac{29.3}{\mathrm{Pr}_{\mathrm{v}}^{3} \sqrt{\mathrm{Re}}}}\left[h_{\mathrm{fg}} \rho_{\mathrm{v}}\left(\frac{\sigma}{g\left(\rho_{\mathrm{l}}-\rho_{\mathrm{v}}\right)}\right)^{3 / 2}+0.1 \frac{\mu_{1}^{2} c_{\mathrm{pl}} \operatorname{Re}^{1.39}}{g\left(\rho_{1}-\rho_{\mathrm{v}}\right)} \Delta T_{\mathrm{s}}\right]
$$

Figure 10 compares eq. (14) to the pool boiling measurements for R513A and R450A from Kedzierski et al. (2018), which were taken on the same test surface and in the same test apparatus as the present measurements. For the entire heat flux test range, the superheats for R513A and R450A were predicted to within $\pm 0.7 \mathrm{~K}$ and $\pm 0.4 \mathrm{~K}$, respectively. On average, the heat flux is predicted to within $\pm 21 \%$ and $\pm 11 \%$ for R513A and R450A, respectively. Larger percent deviations in the heat flux occur for the lowest and highest test heat fluxes. Consequently, for superheats greater than $1.5 \mathrm{~K}$, the average deviation between the measured and predicted heat flux is $\pm 16 \%$ and $\pm 6 \%$ for R513A and R450A, respectively.

Figure 11 illustrates the effect of two of the key fluid parameters on the heat flux as predicted by the pool boiling model. Figure 11 plots the percent change (referenced to the minimum heat flux) in the boiling heat flux as a function of both $h_{\mathrm{fg}} \rho_{\mathrm{v}}$ and $\operatorname{Pr}_{\mathrm{v}}$. The practical ranges of the property values for $h_{\mathrm{fg}} \rho_{\mathrm{v}}$ and $\mathrm{Pr}_{\mathrm{v}}$ are used, which correspond to the range for the present data 
set. The lower and upper abscissa of Fig. 11 plot the $h_{\mathrm{fg}} \rho_{\mathrm{v}}$ and $\operatorname{Pr}_{\mathrm{v}}$, respectively. As immediately apparent, the $h_{\mathrm{fg}} \rho_{\mathrm{v}}$ has a significantly larger influence on the heat flux as compared to $\mathrm{Pr}_{\mathrm{v}}$ where a roughly $600 \%$ change in $h_{\mathrm{fg}} \rho_{\mathrm{v}}$ through its entire range $\left(0.5 \mathrm{MJ} \mathrm{m}^{-3}\right.$ to $3.3 \mathrm{MJ} \mathrm{m}^{-3}$ ) produces a roughly $400 \%$ increase in the heat flux. In comparison, a $67 \%$ decrease in $\operatorname{Pr}_{\mathrm{v}}$ gives an approximate 64 \% increase in the boiling heat flux. Consequently, the $\operatorname{Pr}_{\mathrm{v}}$ is mathematically a stronger governing parameter of the heat flux than $h_{\mathrm{fg}} \rho_{\mathrm{v}}$; however, due to the smaller practical range of $\operatorname{Pr}_{\mathrm{v}}$ as compared to $h_{\mathrm{fg}} \rho_{\mathrm{v}}$, the $\operatorname{Pr}_{\mathrm{v}}$ has a smaller influence.

Open symbols in Fig. 11, representing the properties of the examined test fluids taken from Table 7, more clearly illustrate the influence of properties on the relative performance of the fluids, as previously stated in the Experimental Results Section. For example, the larger heat flux of R1233zd(E) as compared to that of R123 can be seen as a result of the two fluids having very similar $\operatorname{Pr}_{\mathrm{v}}$ (within $1.3 \%$ ), but a larger difference in $h_{\mathrm{fg}} \rho_{\mathrm{v}}$. Here, the $h_{\mathrm{fg}} \rho_{\mathrm{v}}$ for R1233zd(E) is approximately 39 \% larger than that of R123, which causes R1233zd(E) to generally have a larger heat flux. A similar comparison of the $h_{\mathrm{fg}} \rho_{\mathrm{v}}$ for R515A and R1234ze(E) shows that the values of $h_{\mathrm{fg}} \rho_{\mathrm{v}}$ are, conversely, within $1.1 \%$ while the $\operatorname{Pr}_{\mathrm{v}}$ for R515A is roughly 7 \% less than that for R1234ze(E), which leads to the greater heat flux for R515A.

\section{CONCLUSIONS}

The pool boiling performance of a R1234ze(E), R515A, and R1233zd(E) on a flattened, horizontal Turbo-ESP surface was investigated. The study showed that R515A had roughly a $14 \%$ larger heat flux than that of R1234ze(E) for superheats greater than $1 \mathrm{~K}$. Both R515A and R1234ze(E) are replacements for R134a. For heat fluxes between $14 \mathrm{kWm}^{-2}$ and $85 \mathrm{kWm}^{-2}$, R515A and R1234ze(E) exhibited a heat flux that was, on average, $33 \%$ and $17 \%$ larger than that for R134a at the same wall superheat. R1233zd(E) is a replacement for $\mathrm{R} 123$. On average, the heat flux of R1233zd(E) was roughly $18 \%$ larger than that for R123 for heat fluxes between $30 \mathrm{kWm}^{-2}$ and $87 \mathrm{kWm}^{-2}$.

A previously developed prediction model for pure and mixture pool boiling of refrigerants on the Turbo-ESP surface was further improved. The improvement consisted of increasing the statistical significance of the model constants and making them non-dimensional. For most heat fluxes, the model predicted the measured superheat to within $\pm 0.7 \mathrm{~K}$. The model was used to show that the vapor Prandtl number and the product of the latent heat and vapor density significantly influenced the boiling heat flux.

\section{ACKNOWLEDGEMENTS}

This work was funded by the National Institute of Standards and Technology (NIST). Thanks go to D. Han of Ingersoll Rand and to the following NIST personnel for their constructive criticism of the draft manuscript: W. Payne and P. Domanski. Furthermore, the author extends appreciation to A. Heckert of the NIST Statistical Engineering Division for his consultations on the uncertainty analysis. In-kind donations of the test refrigerants by K. Kontomaris of Chemours and S. Yana Motta of Honeywell are greatly appreciated. 


\section{NOMENCLATURE}

English Symbols

$A_{\mathrm{n}} \quad$ regression constant in Table $4 \mathrm{n}=0,1,2,3$

$c_{\mathrm{pl}} \quad$ specific heat of liquid, $\mathrm{J} \mathrm{kg}^{-1} \mathrm{~K}^{-1}$

$D_{\mathrm{b}} \quad$ bubble diameter, $\mathrm{m}$

$g$ gravitational acceleration constant, $9.8 \mathrm{~m} \mathrm{~s}^{-2}$

$h_{\mathrm{fg}} \quad$ latent heat of vaporization, $\mathrm{kJ} \mathrm{kg}^{-1}$

$k$ thermal conductivity, $\mathrm{W} \cdot \mathrm{m}^{-1} \cdot \mathrm{K}^{-1}$

$L \quad$ test surface length shown in Fig. 3, m

$\mathrm{m} \quad$ exponent term in eq. (7) and defined in eq. (8)

$n_{\mathrm{b}} \quad$ number of bubbles per unit time per unit area, $\mathrm{s}^{-1} \mathrm{~m}^{-2}$

$P \quad$ pressure, $\mathrm{Pa}$

$q^{\prime \prime} \quad$ average wall heat flux based on projected area, $\mathrm{W} \cdot \mathrm{m}^{-2}$

$q_{\mathrm{d}}^{\prime \prime} \quad$ heat flux degraded by the mass transfer resistance, $\mathrm{W} \cdot \mathrm{m}^{-2}$

$q_{\mathrm{g}}^{\prime \prime} \quad$ heat flux degraded by the loss of available superheat, $\mathrm{W} \cdot \mathrm{m}^{-2}$

$T$ temperature, $\mathrm{K}$

$u \quad$ velocity, $\mathrm{m} \cdot \mathrm{s}^{-1}$

$U$ expanded uncertainty

$V \quad$ volume, $\mathrm{m}^{3}$

$X \quad$ model terms given in Table 1

Greek symbols

$\beta \quad$ dimensional constant in eq. (8)

$\Gamma \quad$ thickness of superheated layer on bubble, $\mathrm{m}$

$\delta \quad$ thermal boundary layer thickness, $\mathrm{m}$

$\Delta q^{\prime \prime} \quad$ change in boiling heat flux, $\mathrm{W} \cdot \mathrm{m}^{-2}$

$\Delta T_{\mathrm{g}} \quad$ temperature glide: $T_{\mathrm{d}}-T_{\mathrm{b}}, \mathrm{K}$

$\Delta T_{\mathrm{s}} \quad$ wall superheat: $T_{\mathrm{w}}-T_{\mathrm{s}}, \mathrm{K}$

$\theta \quad$ contact angle, degrees

$\mu \quad$ dynamic viscosity, $\mathrm{kg} \cdot \mathrm{m}^{-1} \cdot \mathrm{s}^{-1}$

$\sigma \quad$ surface tension of refrigerant, $\mathrm{N} \cdot \mathrm{m}^{-1}$

$\rho$ density, $\mathrm{kg} \cdot \mathrm{m}^{-3}$

\section{English Subscripts}

d diffusion or dew point

b bubble or bubble point

bL bubble layer

c convection

g glide

l liquid refrigerant

m mixture

q" heat flux

s saturated state, streaming

w wall temperature

v refrigerant vapor 


\section{REFERENCES}

Ahlers J. 2003. Entwicklung einer universellen Gruppenbeitragszustandsgleichung", Thesis, Carl-von-Ossietzky-Universität Oldenburg, 1-144.

Belsley, D. A., Kuh, E., and Welsch, R. E. 1980. Regression Diagnostics: Identifying Influential Data and Sources of Collinearity, New York: Wiley.

Bortolin, S., Azzolin, M., Del Col, D. 2016. Flow boiling of halogenated olefins inside a square cross-section microchannel. Sci. Technol. Built Environ. 22, 1238-1253.

https://doi.org/10.1080/23744731.2016.1229530

Bortolin, S., Col, D. Del. 2014. Flow boiling of a new low-GWP refrigerant inside a single square cross section microchannel. J. Phys. Conf. Ser. 547. https://doi.org/10.1088/1742$\underline{6596 / 547 / 1 / 012019}$

Byun, H.W., Kim, D.H., Yoon, S.H., Song, C.H., Lee, K.H., Kim, O.J. 2017. Pool boiling performance of enhanced tubes on low GWP refrigerants. Appl. Therm. Eng. 123, 791-798. https://doi.org/10.1016/j.applthermaleng.2017.05.009

Chen, T. 2017. Heat transfer during condensation of a Low-GWP refrigerant on an enhanced cylindrical surface. ASME 2017 Heat Transf. Summer Conf. HT 20172.

https://doi.org/10.1115/HT2017-4857

EU. 2014. Regulation (Eu) No 517/2014 of the European Parliament and of the Council of 16 April 2014 on fluorinated greenhouse gases and repealing Regulation (EC) No 842/2006, Official Journal of the European Union, L 150/195, http://data.europa.eu/eli/reg/2014/517/oj.

Fritz, W. 1935. Berechnung des Maximalvolume von Dampfblasen, Physikalische Zeitschrift, 36, 379-388.

Grauso, S., Mastrullo, R., Mauro, A.W., Thome, J.R., Vanoli, G.P. 2013. Flow pattern map, heat transfer and pressure drops during evaporation of R-1234ze(E) and R134a in a horizontal, circular smooth tube: Experiments and assessment of predictive methods. Int. J. Refrig. 36, 478-491. https://doi.org/10.1016/j.ijrefrig.2012.07.016

Gorgy, E. 2016. Nucleate boiling of low-GWP refrigerants on highly enhanced tube surface, Int. J. Heat Mass Transfer, 96, 660-6. https://doi.org/10.1016/j.ijheatmasstransfer.2016.01.057

Gorgy, E, and Eckels, S. 2012. Local heat transfer coefficient for pool boiling of R-134a and R-123 on smooth and enhanced tubes. Int. J. Heat Mass Transfer, 55, 3021-8.

Gorgy, E., and Eckels, S. 2010. Average Heat Transfer Coefficient for Pool Boiling of R134a and R-123 on Smooth and Enhanced Tubes (RP-1316). HVAC\&R Res, 16, 657-76. 
Kedzierski, M. A., and Lin, L. 2019. Pool Boiling of HFO-1336mzz(Z) on a Reentrant Cavity Surface, International Journal of Refrigeration, 104, 476-483, doi.org/10.1016/j.ijrefrig.2019.02.022

Kedzierski, M. A., Lin, L., and, Kang, D. Y. 2018. Pool Boiling of Low GWP Replacements for

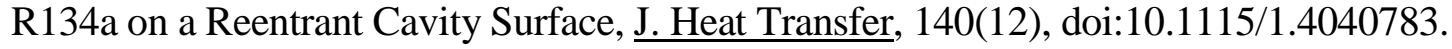

Kedzierski, M. A., and Lin, L. 2018, Effect of IF-WS2 Nanolubricant on R134a Boiling on a Reentrant Cavity Surface; Extensive Measurement and Analysis Details,” NIST Technical Note 2033, U.S. Department of Commerce, Washington, D.C. https://doi.org/10.6028/NIST.TN.2033

Kedzierski, M. A. 2002. Use of Fluorescence to Measure the Lubricant Excess Surface Density During Pool Boiling, Int. J. Refrigeration, 25, 1110-1122.

Kedzierski, M. A. 2001. Use of Fluorescence to Measure the Lubricant Excess Surface Density During Pool Boiling, NISTIR 6727, U.S. Department of Commerce, Washington, D.C.

Kedzierski, M. A. 1999. Ralph L. Webb: A Pioneering Proselytizer for Enhanced Heat Transfer, J. Enhanced Heat Transfer, 6(2-4), 71-78.

Kedzierski, M. A. 1995. Calorimetric and Visual Measurements of R123 Pool Boiling on Four Enhanced Surfaces, NISTIR 5732, U.S. Department of Commerce, Washington.

Kedzierski, M. A. 1993. Simultaneous Visual and Calorimetric Measurements of R11, R123, and R123/Alkylbenzene Nucleate Flow Boiling, Heat Transfer with Alternative Refrigerants, HTD-Vol. 243, H.J. Sauer, Jr., and T.H. Kuehn, Eds., ASME, New York, pp. 27-33.

Kim, D., Lee, D.C. Jang, D.S., Jeon, Y., Kim, Y., 2018. Comparative evaluation of flow boiling heat transfer characteristics of R-1234ze(E) and R-134a in plate heat exchangers with different Chevron angles. Appl. Therm. Eng. 132, 719-729.

https://doi.org/10.1016/j.applthermaleng.2018.01.019

Lee, D.C., Kim, D., Park, S., Lim, J., Kim, Y. 2018. Evaporation heat transfer coefficient and pressure drop of R-1233zd(E) in a brazed plate heat exchanger. Appl. Therm. Eng. 130, 11471155. https://doi.org/10.1016/j.applthermaleng.2017.11.088

Lemmon, E. W., Bell, I. H., Huber, M. L., and McLinden, M. O. 2018. NIST Standard Reference Database 23 (REFPROP), Version 10., National Institute of Standards and Technology, Boulder, CO.

Mikic, B., B, and Rohsenow, W. M. 1969. A New Correlation of Pool-Boiling Data Including the Effect of Heating Surface Characteristics, J. Heat Transfer, 91(2), 245-250. 
Montreal Protocol. 1987. Montreal Protocol on Substances that Deplete the Ozone Layer. United Nations (UN), New York, NY, USA (1987 with subsequent amendments).

Myhre, G., D. Shindell, F.-M. Bréon, W. Collins, J. Fuglestvedt, J. Huang, D. Koch, J.-F. Lamarque, D. Lee, B. Mendoza, T. Nakajima, A. Robock, G. Stephens, T. Takemura and H. Zhang. 2013. Anthropogenic and Natural Radiative Forcing Supplementary Material. In: Climate Change 2013: The Physical Science Basis. Contribution of Working Group I to the Fifth Assessment Report of the Intergovernmental Panel on Climate Change [Stocker, T.F., D. Qin, G.-K. Plattner, M. Tignor, S.K. Allen, J. Boschung, A. Nauels, Y. Xia, V. Bex and P.M. Midgley (eds.)]. Available from www.climatechange2013.org and www.ipcc.ch.

Nagata, R., Kondou, C., Koyama, S. 2016. Comparative assessment of condensation and pool boiling heat transfer on horizontal plain single tubes for R1234ze(E), and R-1233zd(E), Int. J. Refrig. 63 (2016) 157-170.

Peng, D. Y., and Robinson, D. B. 1976. A New Two-Constant Equation of State. Industrial and Engineering Chemistry: Fundamentals. 15, 59-64. doi:10.1021/i160057a011.

Rogers, J. S. 1961. Study of Low-Fin Tube 1929-1960, Wolverine Tube, Inc, Internal Report Neshan-1, p. 8.

Stokes, G. G. 1880. Mathematical and Physical Papers, 1, Cambridge University Press, London, 1880

UNEP. 2016. Amendment to the Montreal Protocol on Substances that Deplete the Ozone Layer, Kigali, 15 October 2016. https://treaties.un.org/doc/Publication/CN/2016/ CN.872.2016-Eng.pdf (accessed July 25, 2017).

van Rooyen, E., Thome, J. R. 2013. Pool boiling data and prediction method for enhanced boiling tubes with R-134a, R-236fa and R-1234ze(E). Int. J. Refrig. 36, 447-455.

https://doi.org/10.1016/j.ijrefrig.2012.11.023

Webb, R. L. 1972. Heat Transfer Surface Having a High Boiling Heat Transfer Coefficient, US patent 3,696,861.

Wilson, E.E. 1915. A Basis for Rational Design of Heat Transfer Apparatus, Trans. ASME, 37, 47-70.

World Meteorological Organiza-tion (WMO). 2006. Scientific Assessment of Ozone Depletion, WMO, Geneva, Switzerland. 
Table 1 Conduction model choice

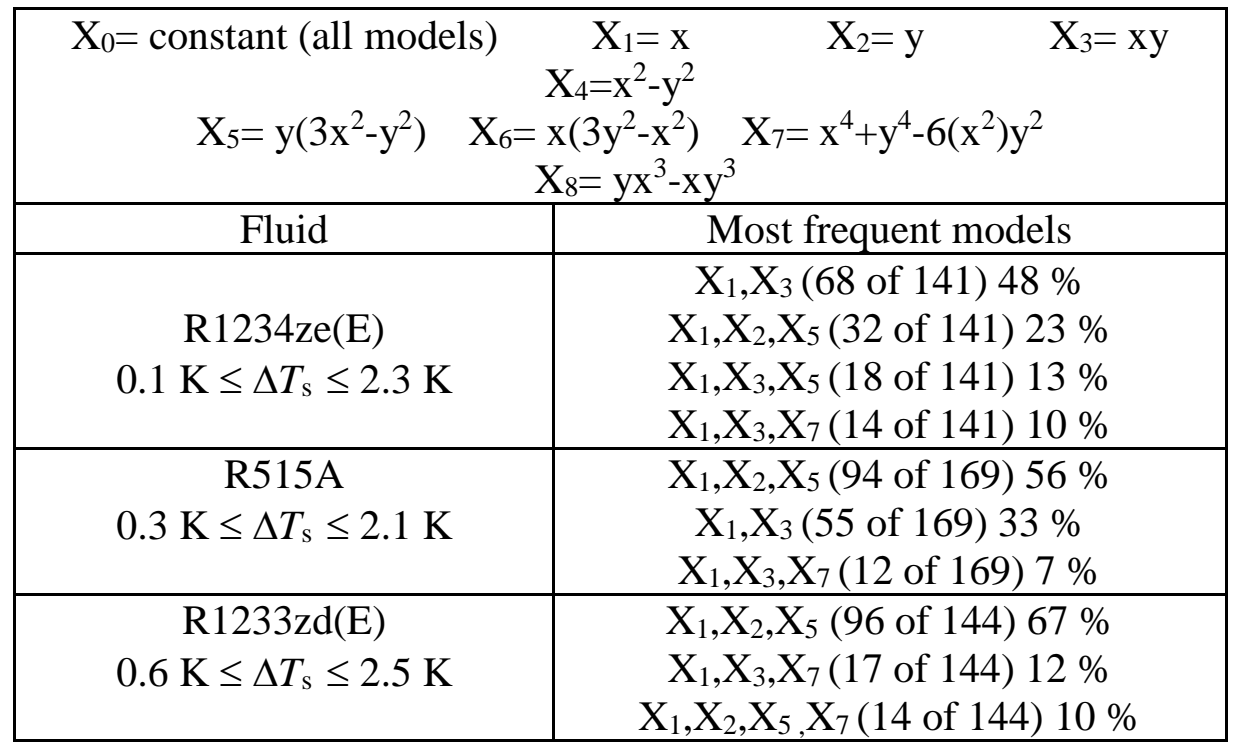


Table 2 Pool boiling data

R1234ze(E), $T_{\mathrm{s}}=277.6 \mathrm{~K}$ File: ESP12A.dat

\begin{tabular}{|c|c|}
\hline $\begin{array}{c}\Delta T_{\mathrm{s}} \\
(\mathrm{K})\end{array}$ & $\begin{array}{c}q^{\prime \prime} \\
\left(\mathrm{Wm}^{-2}\right)\end{array}$ \\
\hline 2.35 & 96729. \\
\hline 2.36 & 96704. \\
\hline 2.24 & 90211. \\
\hline 2.20 & 89927. \\
\hline 2.08 & 83856. \\
\hline 2.07 & 83524. \\
\hline 1.93 & 77399. \\
\hline 1.92 & 77204. \\
\hline 1.76 & 71102. \\
\hline 1.73 & 71027. \\
\hline 1.58 & 64849. \\
\hline 1.56 & 64728. \\
\hline 1.41 & 59171. \\
\hline 1.43 & 59350. \\
\hline 1.24 & 51060. \\
\hline 1.25 & 50873. \\
\hline 1.06 & 43141. \\
\hline 1.04 & 43133. \\
\hline 0.79 & 36377. \\
\hline 0.78 & 36501. \\
\hline 0.59 & 30647. \\
\hline 0.60 & 30625. \\
\hline 0.47 & 24048. \\
\hline 0.44 & 23904. \\
\hline 0.33 & 17180. \\
\hline 2.35 & 96277. \\
\hline 2.37 & 96721. \\
\hline 2.23 & 89316. \\
\hline 2.23 & 89466. \\
\hline 2.09 & 82892. \\
\hline 2.08 & 82956. \\
\hline 1.89 & 77221. \\
\hline 1.88 & 77152. \\
\hline 1.74 & 71253. \\
\hline 1.74 & 71321. \\
\hline 1.58 & 64698. \\
\hline 1.58 & 64770. \\
\hline 1.44 & 58171. \\
\hline 1.41 & 58481. \\
\hline 1.20 & 50347. \\
\hline 1.19 & 50281. \\
\hline 0.94 & 43376. \\
\hline 0.91 & 43105. \\
\hline 0.65 & 34512. \\
\hline 0.65 & 34636. \\
\hline 0.51 & 28426. \\
\hline 0.50 & 28328. \\
\hline & \\
\hline
\end{tabular}

\begin{tabular}{|l|l|}
\hline 0.35 & 20656. \\
\hline 0.36 & 20682. \\
\hline 2.34 & 9580. \\
\hline 2.30 & 95657. \\
\hline 2.13 & 90237. \\
\hline 2.15 & $9074 .$. \\
\hline 2.01 & 83970. \\
\hline 2.00 & 84053. \\
\hline 1.85 & 77524. \\
\hline 1.88 & 77703. \\
\hline 1.71 & 71591. \\
\hline 1.69 & 71250. \\
\hline 1.58 & 64783. \\
\hline 1.56 & 64911. \\
\hline 1.36 & 58795. \\
\hline 1.37 & 59136. \\
\hline 1.18 & 5117. \\
\hline 1.16 & 50955. \\
\hline 0.96 & 43306. \\
\hline 0.94 & 43035. \\
\hline 0.70 & 36670. \\
\hline 0.72 & 36788. \\
\hline 0.53 & 30307. \\
\hline 0.51 & 30167. \\
\hline 0.26 & 22981. \\
\hline 0.25 & 23189. \\
\hline 0.17 & 14846. \\
\hline 2.32 & 97013. \\
\hline 2.31 & 96824. \\
\hline 2.12 & 88172. \\
\hline 2.10 & 88154. \\
\hline 1.92 & 7971. \\
\hline 1.89 & 79593. \\
\hline 1.69 & 71159. \\
\hline 1.69 & 71271. \\
\hline 1.50 & 62910. \\
\hline 1.47 & 62818. \\
\hline 1.31 & 54457. \\
\hline 1.28 & 54357. \\
\hline 1.11 & 47207. \\
\hline 1.11 & 47247. \\
\hline 0.88 & 40506. \\
\hline 0.86 & 40256. \\
\hline 0.68 & 33234. \\
\hline 0.67 & 33194. \\
\hline 0.54 & 28042. \\
\hline 0.56 & 27932. \\
\hline 0.44 & 23636. \\
\hline 0.43 & 23480. \\
\hline 0.32 & 19321. \\
\hline 0.29 & 19364. \\
\hline & \\
\hline
\end{tabular}

\begin{tabular}{|l|l|}
\hline 0.21 & 14529. \\
\hline 2.19 & 94992. \\
\hline 2.17 & 94732. \\
\hline 1.99 & 87266. \\
\hline 1.98 & 87332. \\
\hline 1.84 & 81834. \\
\hline 1.85 & 81955. \\
\hline 1.73 & 75046. \\
\hline 1.74 & 75117. \\
\hline 1.58 & 68848. \\
\hline 1.57 & 68937. \\
\hline 1.45 & 63523. \\
\hline 1.44 & 63466. \\
\hline 1.26 & 55451. \\
\hline 1.24 & 55392. \\
\hline 1.02 & 48078. \\
\hline 1.02 & 47885. \\
\hline 0.82 & 40051. \\
\hline 0.81 & 39867. \\
\hline 0.61 & 33408. \\
\hline 0.59 & 33601. \\
\hline 0.45 & 27427. \\
\hline 0.45 & 27342. \\
\hline 0.36 & 20828. \\
\hline 2.26 & 96246. \\
\hline 2.25 & 96150. \\
\hline 2.06 & 87939. \\
\hline 2.04 & 88075. \\
\hline 1.91 & 82473. \\
\hline 1.91 & 82257. \\
\hline 1.78 & 76485. \\
\hline 1.76 & 76333. \\
\hline 1.66 & 69461. \\
\hline 1.62 & 69393. \\
\hline 1.46 & 63783. \\
\hline 1.46 & 63648. \\
\hline 1.29 & 56284. \\
\hline 1.29 & 56101. \\
\hline 1.04 & 46496. \\
\hline 1.02 & 46378. \\
\hline 0.74 & 38464. \\
\hline 0.72 & 38542. \\
\hline 0.51 & 32775. \\
\hline 0.50 & 32628. \\
\hline 0.34 & 26563. \\
\hline 0.33 & 26733. \\
\hline 0.24 & 20279. \\
\hline 0.24 & 20277. \\
\hline & \\
\hline
\end{tabular}




\begin{tabular}{|c|c|c|c|}
\hline \multirow{2}{*}{\multicolumn{2}{|c|}{$\begin{array}{l}\text { R515A, } T_{\mathrm{s}}=277.6 \mathrm{~K} \\
\text { File: ESPDRA.dat }\end{array}$}} & 1.79 & 82398. \\
\hline & & 1.64 & 76620 \\
\hline \multirow{2}{*}{$\begin{array}{l}\Delta T_{\mathrm{s}} \\
(\mathrm{K})\end{array}$} & \multirow{2}{*}{$\begin{array}{c}q^{\prime \prime} \\
\left(\mathrm{Wm}^{-2}\right)\end{array}$} & 1.62 & 76608 \\
\hline & & 1.46 & 71169 \\
\hline 2.12 & 96298. & 1.44 & 71131. \\
\hline 2.10 & 96289. & 1.29 & 65978 \\
\hline 1.98 & 89526. & 1.28 & 66107 \\
\hline 1.98 & 89511. & 1.12 & 57737. \\
\hline 1.83 & 82978. & 1.11 & 57677 \\
\hline 1.84 & 83232. & 0.91 & 50573 \\
\hline 1.67 & 77491. & 0.89 & 50477 \\
\hline 1.67 & 77491. & 0.80 & 42378 \\
\hline 1.54 & 71430. & 0.79 & 42145 \\
\hline 1.53 & 71430. & 0.59 & 35080 \\
\hline 1.38 & 65576. & 0.59 & 35122 \\
\hline 1.37 & 65452. & 0.45 & 28202 \\
\hline 1.16 & 57831. & 0.46 & 28337 \\
\hline 1.16 & 57905. & 0.35 & 23680 \\
\hline 0.97 & 50111. & 0.33 & 23753 \\
\hline 0.96 & 50171. & 0.30 & 18972 \\
\hline 0.80 & 42611. & 2.06 & 96770 \\
\hline 0.79 & 42601. & 2.07 & 97141. \\
\hline 0.61 & 35572. & 1.96 & 89542 \\
\hline 0.61 & 35562. & 1.97 & 89947. \\
\hline 0.49 & 28936. & 1.83 & 83728 \\
\hline 0.49 & 28883. & 1.81 & 83698. \\
\hline 0.47 & 23017. & 1.64 & 76544 \\
\hline 0.45 & 23039. & 1.65 & 76769 \\
\hline 0.32 & 18538. & 1.48 & 71014 \\
\hline 2.05 & 95837. & 1.47 & 70962. \\
\hline $\begin{array}{l}2.08 \\
1.94\end{array}$ & 95877. & $\frac{1.34}{1.32}$ & 65477. \\
\hline $\begin{array}{l}1.94 \\
1.93\end{array}$ & 89808. & $\begin{array}{l}1.32 \\
1.14\end{array}$ & $\frac{65423 .}{58585}$ \\
\hline $\begin{array}{l}1.93 \\
1.77\end{array}$ & 89780. & 1.13 & $\begin{array}{l}58585 \\
58426\end{array}$ \\
\hline $\begin{array}{l}1.77 \\
1.78 \\
\end{array}$ & $\frac{83975 .}{84385}$ & 0.97 & $\begin{array}{r}58426 \\
50111 .\end{array}$ \\
\hline $\begin{array}{l}1.78 \\
1.68 \\
\end{array}$ & $\frac{84385 .}{78220 .}$ & 0.97 & 50015 \\
\hline 1.66 & 78193. & 0.83 & 41714 \\
\hline 1.53 & 72149. & 0.83 & 41671. \\
\hline 1.54 & 71999. & 0.61 & 34524 \\
\hline 1.36 & 66094. & 0.62 & 34686 \\
\hline 1.37 & 66131. & 0.49 & 28395 \\
\hline 1.17 & 58294. & 0.48 & 28392 \\
\hline 1.14 & 58221. & 0.47 & 23161. \\
\hline 0.96 & 50576. & 0.47 & 22959 \\
\hline 0.96 & 50595. & 0.27 & 17331. \\
\hline 0.80 & 43574. & 2.06 & 95240. \\
\hline 0.77 & 43505. & 2.05 & 95264 \\
\hline 0.60 & 35775. & 1.92 & 89743 \\
\hline 0.63 & 35882. & 1.92 & 89776 \\
\hline 0.47 & 29111. & 1.80 & 83780 \\
\hline 0.47 & 29180. & 1.79 & 83610 \\
\hline 0.42 & 23421. & 1.66 & 77586 \\
\hline 0.41 & 23376. & 1.66 & 77551. \\
\hline 0.29 & 19015. & 1.48 & 71730 \\
\hline 2.05 & 95044. & 1.49 & 71755 \\
\hline 2.05 & 95009. & 1.33 & 66155 \\
\hline 1.88 & 89440. & 1.32 & 66082 \\
\hline 1.89 & 89555. & 1.13 & 58461. \\
\hline 1.79 & 82417. & 1.13 & 58377 \\
\hline
\end{tabular}

\begin{tabular}{|l|l|}
\hline 0.94 & 50669. \\
\hline 0.93 & 50657. \\
\hline 0.73 & 42825. \\
\hline 0.72 & 42842. \\
\hline 0.58 & 35801. \\
\hline 0.58 & 3571. \\
\hline 0.47 & 30444. \\
\hline 0.49 & 30142. \\
\hline 0.37 & 24030. \\
\hline 0.36 & 23801. \\
\hline 0.24 & 17790. \\
\hline 2.08 & 95300. \\
\hline 2.08 & 95261. \\
\hline 1.94 & 89715. \\
\hline 1.92 & 8973. \\
\hline 1.76 & 83541. \\
\hline 1.78 & 83728. \\
\hline 1.61 & 77925. \\
\hline 1.63 & 78008. \\
\hline 1.48 & 71479. \\
\hline 1.50 & 71371. \\
\hline 1.31 & 65683. \\
\hline 1.32 & 65634. \\
\hline 1.12 & 58231. \\
\hline 1.12 & 58231. \\
\hline 0.87 & 50729. \\
\hline 0.90 & 50845. \\
\hline 0.73 & 42783. \\
\hline 0.74 & 42684. \\
\hline 0.47 & 31786. \\
\hline 0.47 & 31686. \\
\hline 0.40 & 26716. \\
\hline 2.01 & 94995. \\
\hline 2.00 & 95064. \\
\hline 1.87 & 89381. \\
\hline 1.86 & 89285. \\
\hline 1.73 & 83445. \\
\hline 1.72 & 83468. \\
\hline 1.60 & 77463. \\
\hline 1.60 & 77418. \\
\hline 1.45 & 71259. \\
\hline 1.47 & 71107. \\
\hline 1.32 & 65540. \\
\hline 1.30 & 65653. \\
\hline 1.06 & 57319. \\
\hline 1.09 & 57493. \\
\hline 0.87 & 50114. \\
\hline 0.86 & 50110. \\
\hline 0.69 & 42974. \\
\hline 0.70 & 43007. \\
\hline 0.60 & 35097. \\
\hline 0.61 & 35084. \\
\hline 0.52 & 29801. \\
\hline 0.52 & 29833. \\
\hline 0.36 & 23751. \\
\hline 0.29 & 23701. \\
\hline 0.27 & 17449. \\
\hline & \\
\hline
\end{tabular}




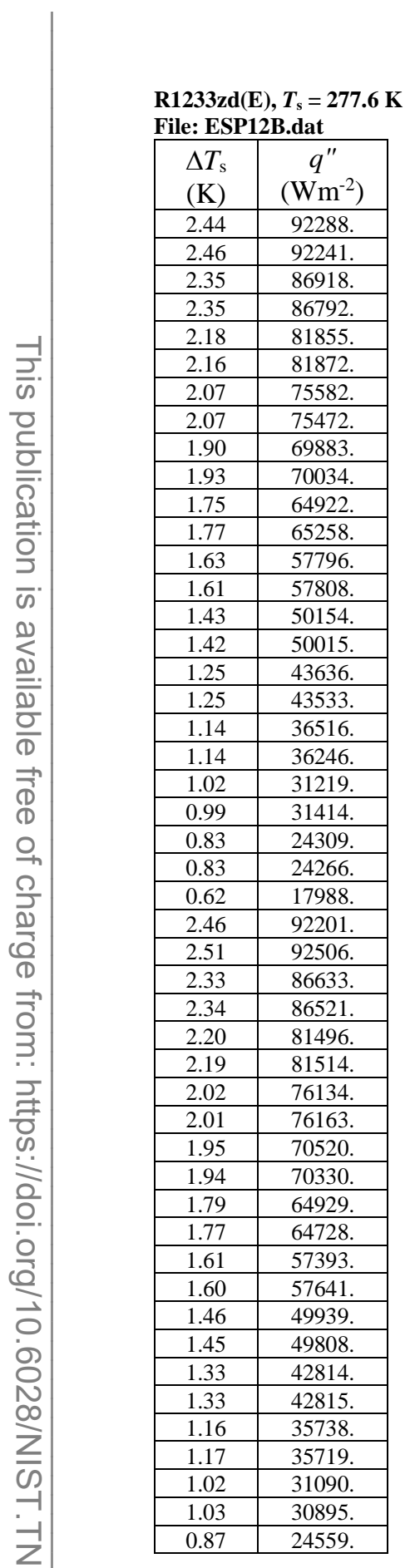

\begin{tabular}{|l|l|}
\hline 0.86 & 24388. \\
\hline 0.67 & 18081. \\
\hline 2.34 & 93105. \\
\hline 2.34 & 93113. \\
\hline 2.22 & 87835. \\
\hline 2.19 & 87449. \\
\hline 2.11 & 81993. \\
\hline 2.10 & 81701. \\
\hline 1.97 & 76098. \\
\hline 1.97 & 76302. \\
\hline 1.86 & 70347. \\
\hline 1.85 & 70359. \\
\hline 1.73 & 64918. \\
\hline 1.72 & 64947. \\
\hline 1.54 & 57714. \\
\hline 1.55 & 57647. \\
\hline 1.35 & 50344. \\
\hline 1.38 & 50394. \\
\hline 1.23 & 42664. \\
\hline 1.22 & 42566. \\
\hline 1.06 & 35955. \\
\hline 1.05 & 35826. \\
\hline 0.95 & 31002. \\
\hline 0.92 & 31028. \\
\hline 0.81 & 24320. \\
\hline 0.80 & 24080. \\
\hline 0.58 & 17983. \\
\hline 2.36 & 91294. \\
\hline 2.35 & 91438. \\
\hline 2.23 & 86032. \\
\hline 2.23 & 86329. \\
\hline 2.12 & 81565. \\
\hline 2.11 & 81472. \\
\hline 2.00 & 75755. \\
\hline 2.01 & 75497. \\
\hline 1.91 & 69956. \\
\hline 1.91 & 69930. \\
\hline 1.79 & 64726. \\
\hline 1.75 & 64508. \\
\hline 1.62 & 57250. \\
\hline 1.60 & 57159. \\
\hline 1.46 & 49332. \\
\hline 1.45 & 49273. \\
\hline 1.32 & 41918. \\
\hline 1.32 & 41732. \\
\hline 1.18 & 35223. \\
\hline 1.17 & 35388. \\
\hline 1.04 & 30633. \\
\hline 1.04 & 30746. \\
\hline 0.87 & 23230. \\
\hline 0.87 & 23114. \\
\hline 0.65 & 17062. \\
\hline 2.46 & 92006. \\
\hline & \\
\hline
\end{tabular}

\begin{tabular}{|l|l|}
\hline 2.47 & 92220. \\
\hline 2.33 & 86526. \\
\hline 2.32 & 86833. \\
\hline 2.16 & 81168. \\
\hline 2.18 & 81359. \\
\hline 2.09 & 76346. \\
\hline 2.06 & 76575. \\
\hline 1.90 & 70296. \\
\hline 1.93 & 70500. \\
\hline 1.78 & 64210. \\
\hline 1.79 & 64228. \\
\hline 1.57 & 57396. \\
\hline 1.59 & 57379. \\
\hline 1.43 & 50136. \\
\hline 1.40 & 50150. \\
\hline 1.25 & 43130. \\
\hline 1.25 & 43125. \\
\hline 1.13 & 35267. \\
\hline 1.15 & 35139. \\
\hline 0.98 & 30760. \\
\hline 0.99 & 30713. \\
\hline 0.79 & 24335. \\
\hline 0.78 & 24588. \\
\hline 0.63 & 17675. \\
\hline 2.47 & 90055. \\
\hline 2.47 & 90068. \\
\hline 2.34 & 85028. \\
\hline 2.30 & 84879. \\
\hline 2.19 & 79825. \\
\hline 2.19 & 79480. \\
\hline 2.07 & 74710. \\
\hline 2.04 & 74804. \\
\hline 1.93 & 69823. \\
\hline 1.92 & 69885. \\
\hline 1.85 & 64497. \\
\hline 1.83 & 64387. \\
\hline 1.69 & 56784. \\
\hline 1.68 & 56668. \\
\hline 1.55 & 49213. \\
\hline 1.54 & 49319. \\
\hline 1.37 & 41984. \\
\hline 1.38 & 41838. \\
\hline 1.22 & 35165. \\
\hline 1.19 & 35312. \\
\hline 1.07 & 30708. \\
\hline 1.08 & 30633. \\
\hline 0.90 & 23896. \\
\hline 0.87 & 24172. \\
\hline 0.73 & 17500. \\
\hline 0.73 & 17160. \\
\hline & \\
\hline
\end{tabular}


Table 3 Number of test days and data points

\begin{tabular}{|c|c|c|}
\hline Fluid & Number of days & $\begin{array}{c}\text { Number of data points/ } \\
\text { Number of data points with } \\
\text { outliers removed }\end{array}$ \\
\hline $\begin{array}{c}\text { R1234ze(E) } \\
0.1 \mathrm{~K} \leq \Delta T_{\mathrm{s}} \leq 2.3 \mathrm{~K}\end{array}$ & 6 & $145 / 141$ \\
\hline $\mathrm{R} 515 \mathrm{~A}$ & 7 & $171 / 169$ \\
\hline $0.3 \mathrm{~K} \leq \Delta T_{\mathrm{s}} \leq 2.1 \mathrm{~K}$ & & $150 / 144$ \\
\hline $\mathrm{R} 1233 \mathrm{zd}(\mathrm{E})$ & 6 & \\
\hline $0.6 \mathrm{~K} \leq \Delta T_{\mathrm{s}} \leq 2.5 \mathrm{~K}$ & & \\
\hline
\end{tabular}

Table 4 Estimated parameters for cubic boiling curve fits

$$
\Delta T_{\mathrm{s}}=\mathrm{A}_{0}+\mathrm{A}_{1} q "+\mathrm{A}_{2} q^{\prime 2}+\mathrm{A}_{3} q^{\prime 3}
$$

$\Delta T_{\mathrm{s}}$ in kelvin and $q$ " in $\mathrm{Wm}^{-2}$

\begin{tabular}{|c|c|c|c|c|}
\hline Fluid & $\mathrm{A}_{0}$ & $\mathrm{~A}_{1}$ & $\mathrm{~A}_{2}$ & $\mathrm{~A}_{3}$ \\
\hline $\mathrm{R} 1234 \mathrm{ze}(\mathrm{E})$ & & & & \\
$0.1 \mathrm{~K} \leq \Delta T_{\mathrm{s}} \leq 2.3 \mathrm{~K}$ & -0.2613331 & $2.499168 \times 10^{-5}$ & $1.017453 \times 10^{-10}$ & $-9.084801 \times 10^{-16}$ \\
\hline $\begin{array}{c}\mathrm{R} 515 \mathrm{~A} \\
0.3 \mathrm{~K} \leq \Delta T_{\mathrm{s}} \leq 2.1 \mathrm{~K}\end{array}$ & 0.2045581 & $-6.823115 \times 10^{-7}$ & $4.056600 \times 10^{-10}$ & $-2.042998 \times 10^{-15}$ \\
\hline $\mathrm{R} 1233 \mathrm{zd}(\mathrm{E})$ & & & & \\
$0.6 \mathrm{~K} \leq \Delta T_{\mathrm{s}} \leq 2.5 \mathrm{~K}$ & 0.08620677 & $3.706327 \times 10^{-5}$ & $-2.769434 \times 10^{-10}$ & $1.666566 \times 10^{-15}$ \\
\hline
\end{tabular}

Table 5 Residual standard deviation of $\Delta T_{\mathrm{s}}$

\begin{tabular}{|c|c|}
\hline Fluid & $(\mathrm{K})$ \\
\hline $\mathrm{R} 1234 \mathrm{ze}(\mathrm{E})$ & \\
$0.1 \mathrm{~K} \leq \Delta T_{\mathrm{s}} \leq 2.3 \mathrm{~K}$ & 0.06 \\
\hline $\mathrm{R} 515 \mathrm{~A}$ & \\
$0.3 \mathrm{~K} \leq \Delta T_{\mathrm{s}} \leq 2.1 \mathrm{~K}$ & 0.04 \\
\hline $\mathrm{R} 1233 \mathrm{zd}(\mathrm{E})$ & \\
$0.6 \mathrm{~K} \leq \Delta T_{\mathrm{s}} \leq 2.5 \mathrm{~K}$ & 0.05 \\
\hline
\end{tabular}


Table 6 Average magnitude of $95 \%$ multi-use confidence interval for mean $\Delta T_{\mathrm{s}}$

\begin{tabular}{|c|c|}
\hline Fluid & $U(\mathrm{~K})$ \\
\hline $\begin{array}{c}\mathrm{R} 1234 \mathrm{ze}(\mathrm{E}) \\
\mathrm{K} \leq \Delta T_{\mathrm{s}} \leq 2.3 \mathrm{~K}\end{array}$ & 0.03 \\
\hline $\mathrm{R} 515 \mathrm{~A}$ & 0.02 \\
\hline $0.3 \mathrm{~K} \leq \Delta T_{\mathrm{s}} \leq 2.1 \mathrm{~K}$ & 0.03 \\
\hline $\mathrm{R} 1233 \mathrm{zd}(\mathrm{E})$ & \\
\hline $0.6 \mathrm{~K} \leq \Delta T_{\mathrm{s}} \leq 2.5 \mathrm{~K}$ & \\
\hline
\end{tabular}

Table 7 Selected fluid properties of test refrigerants at saturation (277.6 K) using REFPROP 10.0 default equations (Lemmon et al., 2018)

\begin{tabular}{|c|c|c|c|c|c|c|c|c|c|}
\hline Fluid & $\begin{array}{c}P_{\mathrm{v}} \\
(\mathrm{kPa})\end{array}$ & $\begin{array}{c}\operatorname{Pr}_{\mathrm{v}} \\
(-)\end{array}$ & $\begin{array}{c}k_{\mathrm{l}} \\
\left(\mathrm{mWm}^{-1} \mathrm{~K}^{-1}\right)\end{array}$ & $\begin{array}{c}\mu_{\mathrm{l}} \\
\left(\mu \mathrm{kg} \cdot \mathrm{m}^{-1} \mathrm{~s}^{-1}\right)\end{array}$ & $\begin{array}{c}\sigma \\
\left(\mathrm{N} \cdot \mathrm{m}^{-1}\right)\end{array}$ & $\begin{array}{c}\rho_{\mathrm{l}} \\
\left(\mathrm{kg} \mathrm{m}^{-3}\right)\end{array}$ & $\begin{array}{c}\rho_{\mathrm{v}} \\
\left(\mathrm{kg} \mathrm{m}^{-3}\right)\end{array}$ & $\begin{array}{c}h_{\mathrm{fg}} \\
\left(\mathrm{kJ} \mathrm{kg}^{-1}\right)\end{array}$ & $\begin{array}{c}C_{\mathrm{pl}} \\
\left(\mathrm{kJkg}^{-1} \mathrm{~K}^{-1}\right)\end{array}$ \\
\hline R1234ze(E) & 254.34 & 0.827 & 81.441 & 247.80 & 0.011742 & 1227.0 & 13.66 & 181.32 & 1.3285 \\
\hline R515A & 252.31 & 0.770 & 84.083 & 279.27 & 0.011483 & 1250.9 & 14.28 & 175.43 & 1.2893 \\
\hline R134a & 343.02 & 0.840 & 90.048 & 251.86 & 0.010806 & 1279.9 & 16.8 & 195.17 & 1.3536 \\
\hline R1233zd(E) & 58.308 & 0.833 & 80.901 & 353.57 & 0.017314 & 1311.1 & 3.38 & 201.46 & 1.1838 \\
\hline R123 & 39.85 & 0.823 & 82.387 & 533.98 & 0.017654 & 1515.3 & 2.7 & 179.69 & 0.9953 \\
\hline
\end{tabular}

${ }^{5}$ The volume-translated Peng-Robinson model (Ahlers, 2003) was used for all R515A properties except for the liquid and vapor densities. 


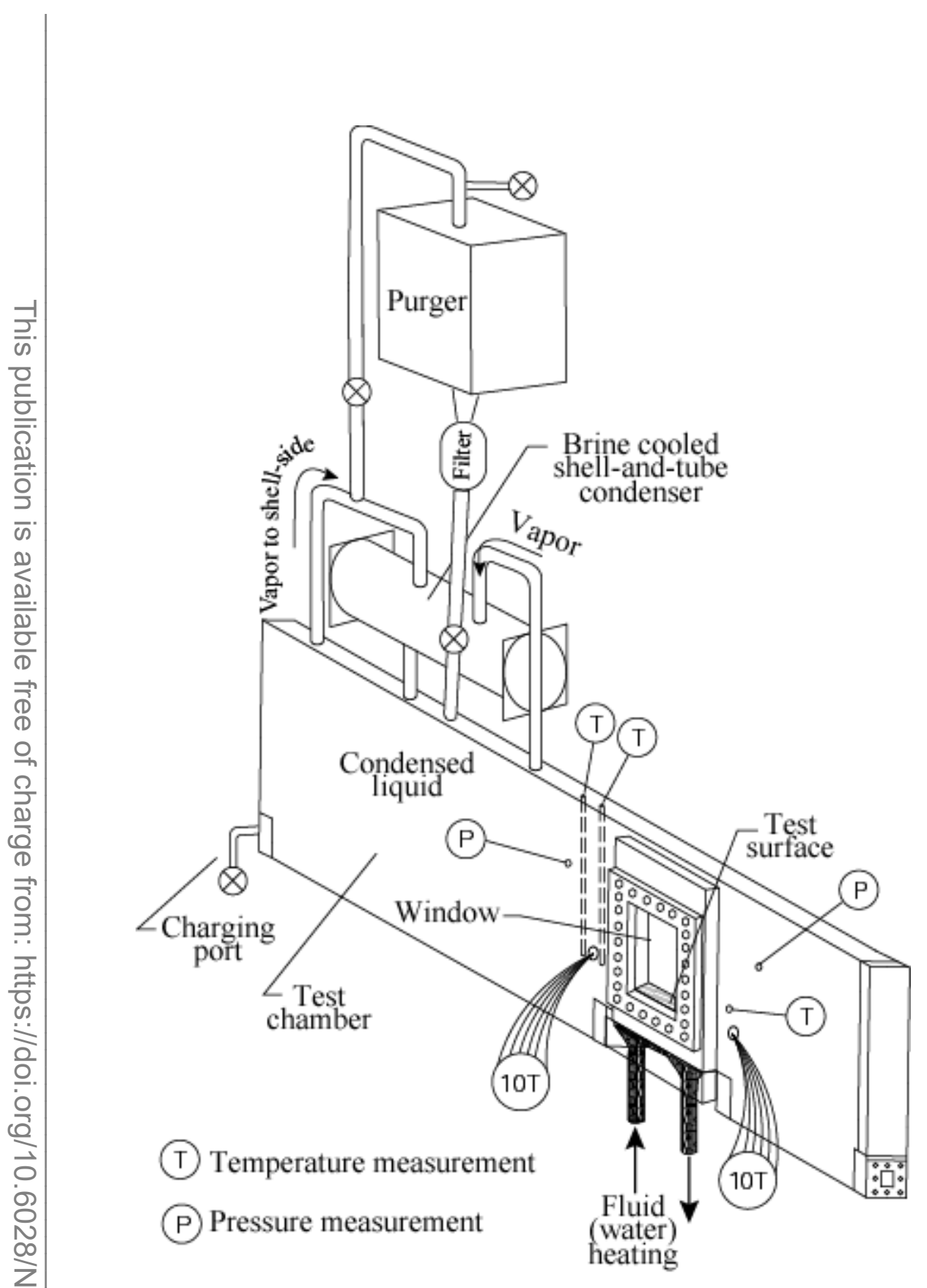

Fig. 1 Schematic of test apparatus 


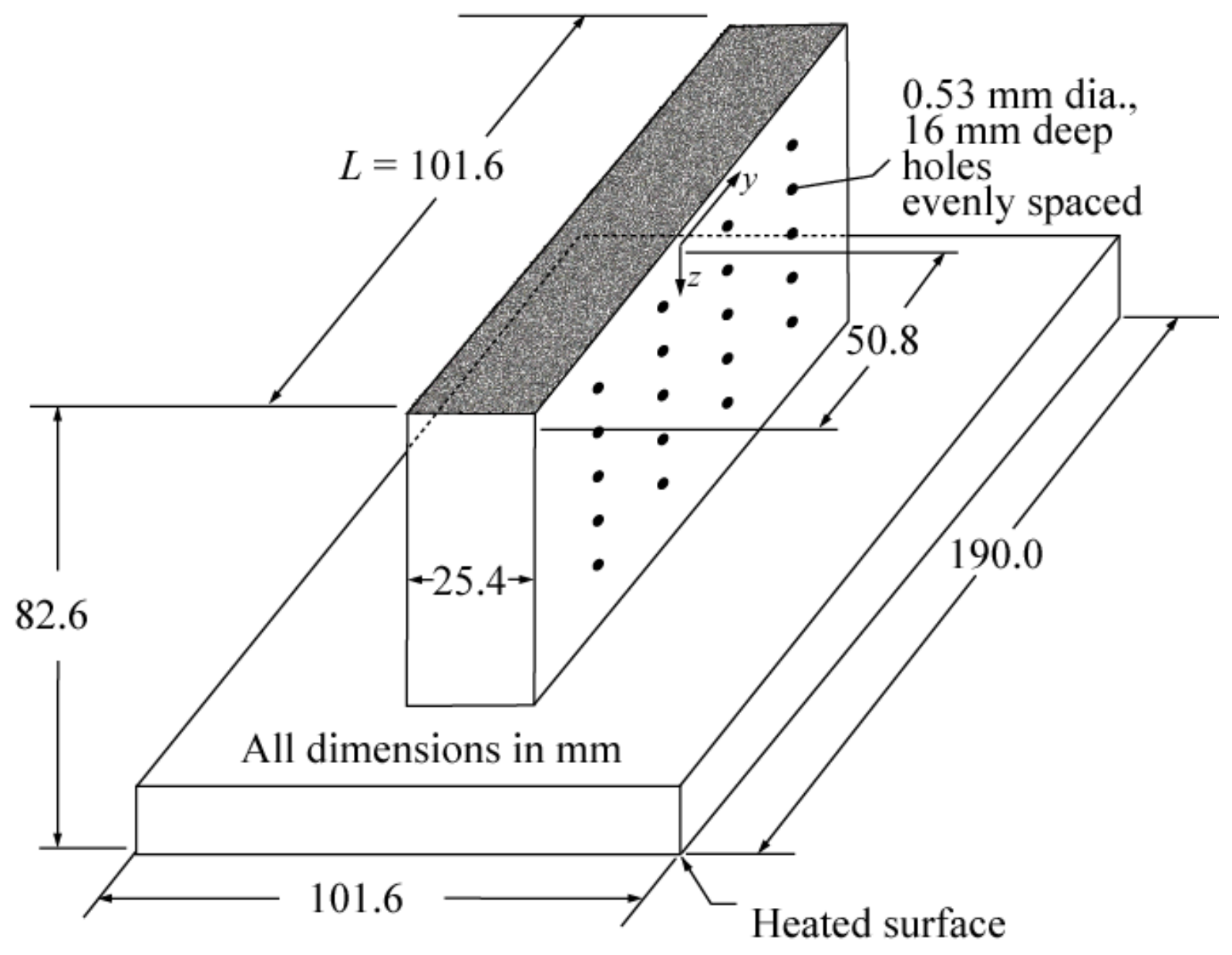

Fig. 2 OFHC copper flat test plate with Turbo-ESP surface and thermocouple coordinate system 


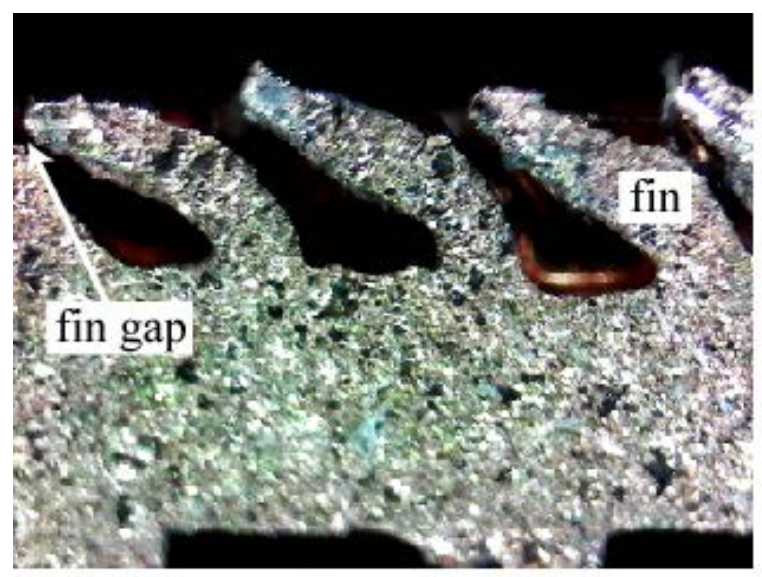

$-0.1 \mathrm{~mm}$

SIDE VIEW

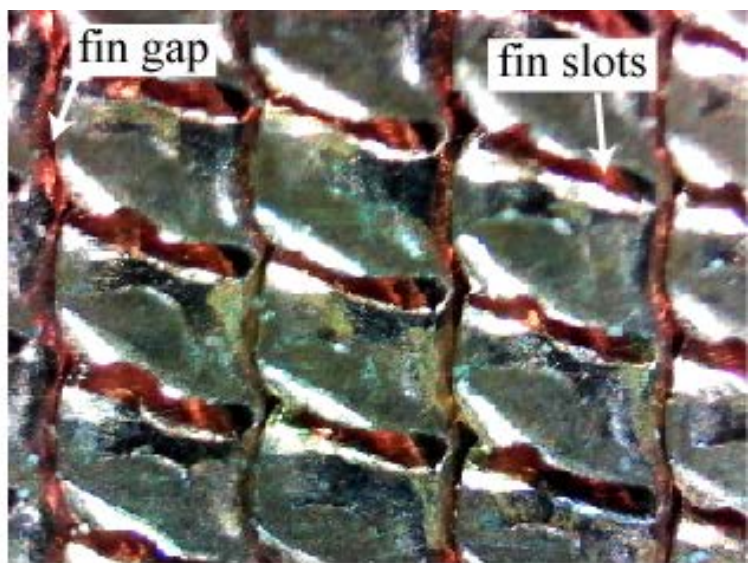

$-0.1 \mathrm{~mm}$

TOP VIEW

Fig. 3 Photograph of Turbo-ESP surface 


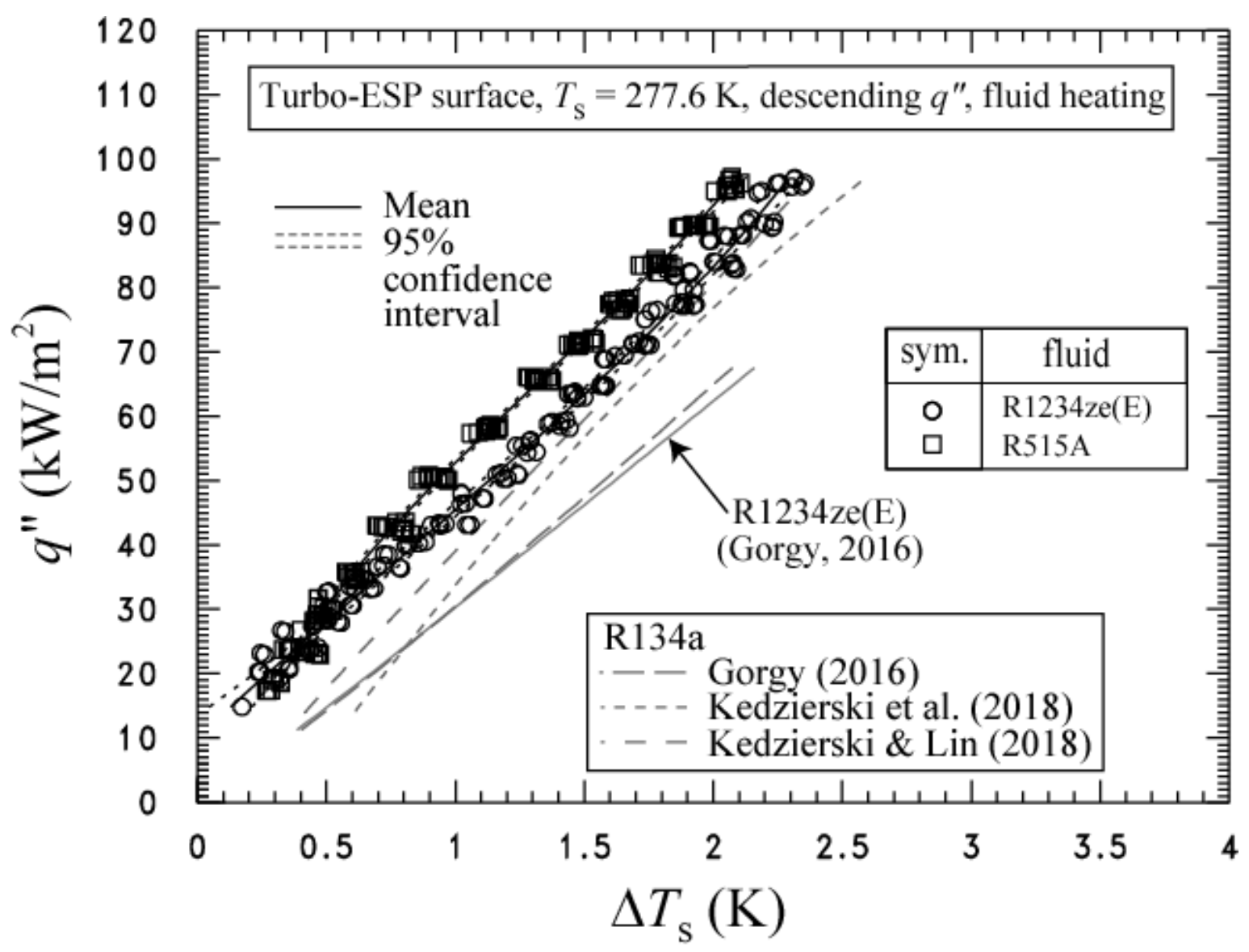

Fig. 4 Comparison of boiling curves for R1234ze(E), R515A, and R134a at 277.6 K 


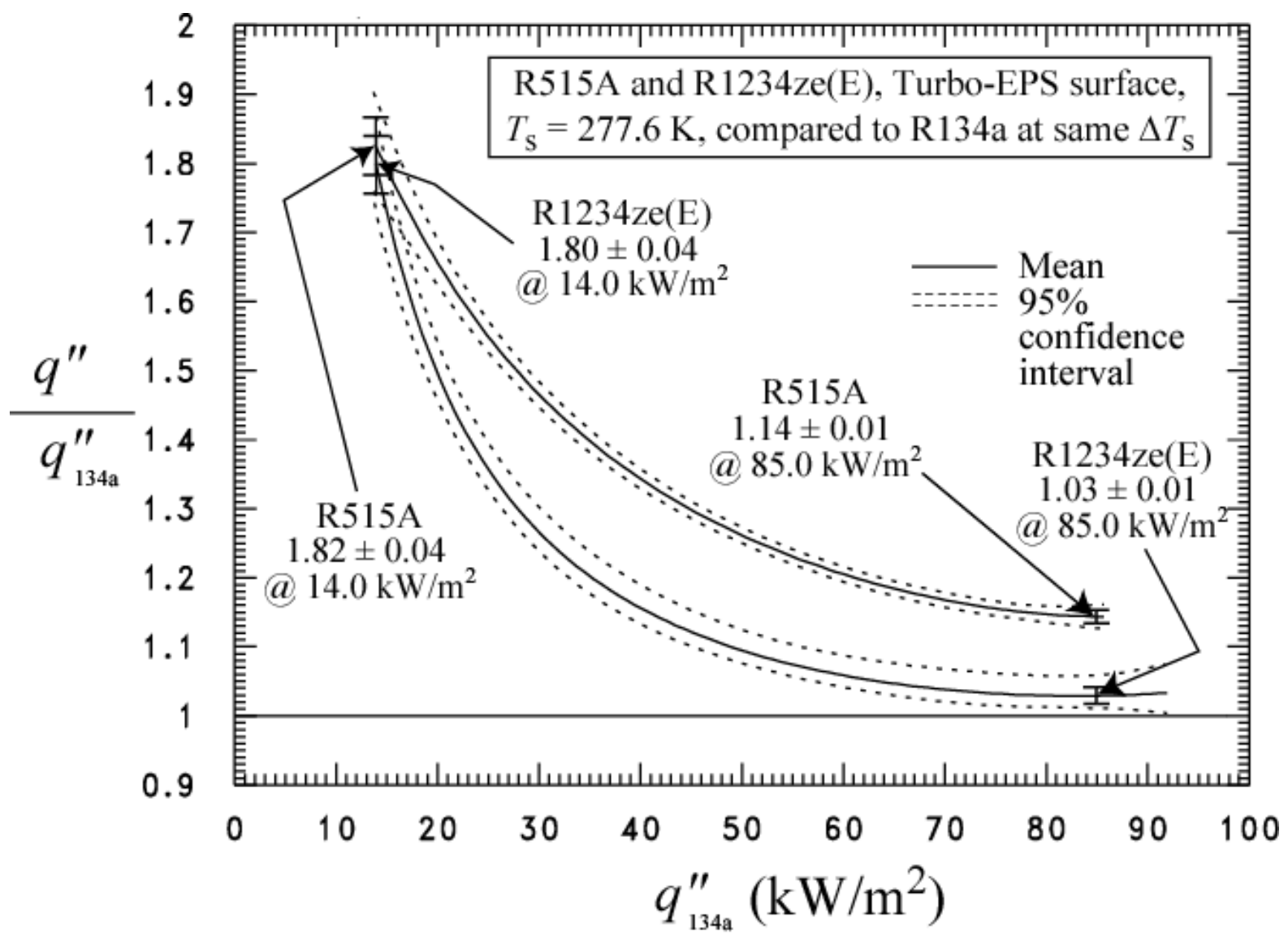

Fig. 5 Comparison of R515A and R1234ze(E) heat fluxes to that for R134a at the same wall superheat 


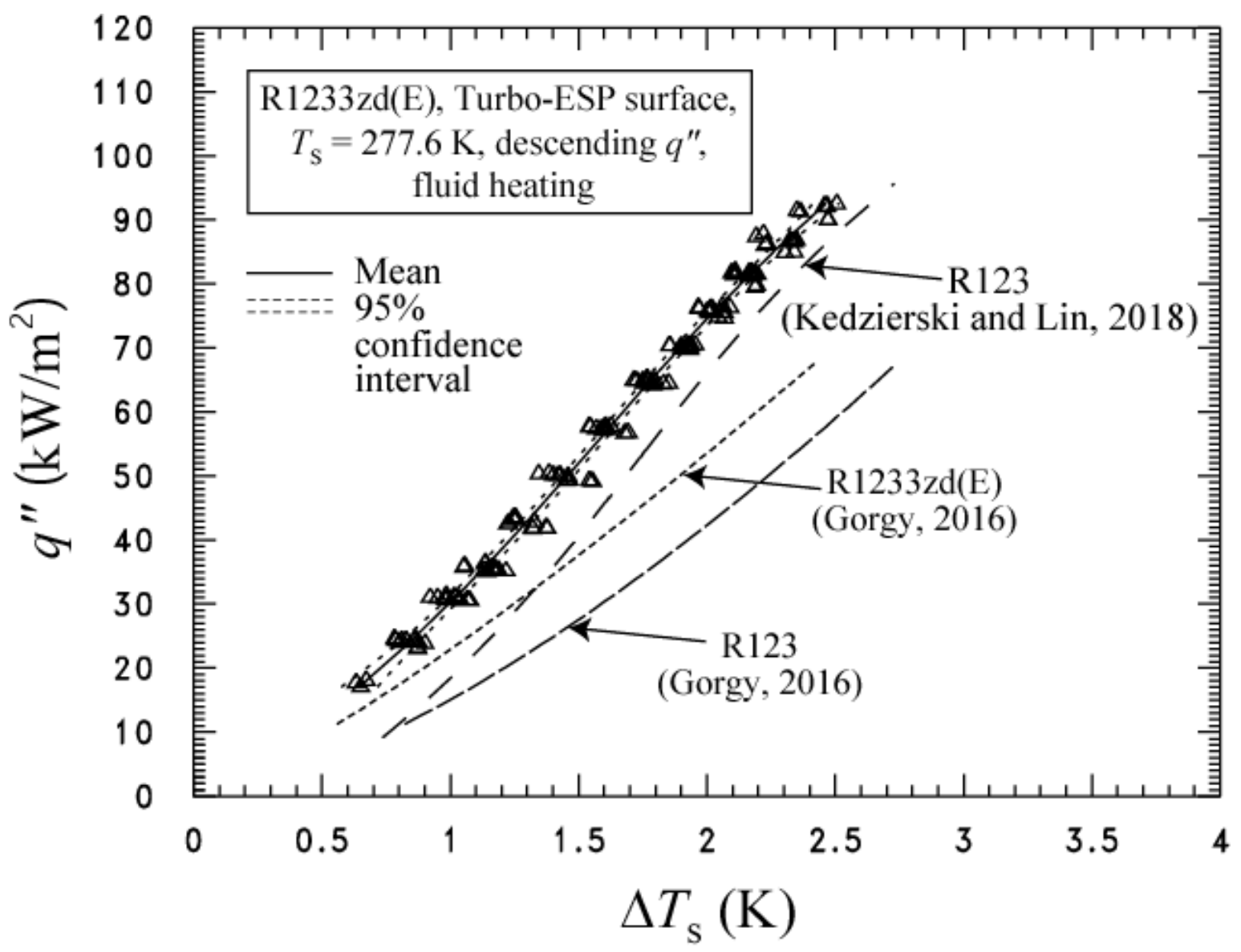

Fig. 6 Comparison of boiling curves for R1233zd(E) and R123 at $277.6 \mathrm{~K}$ 


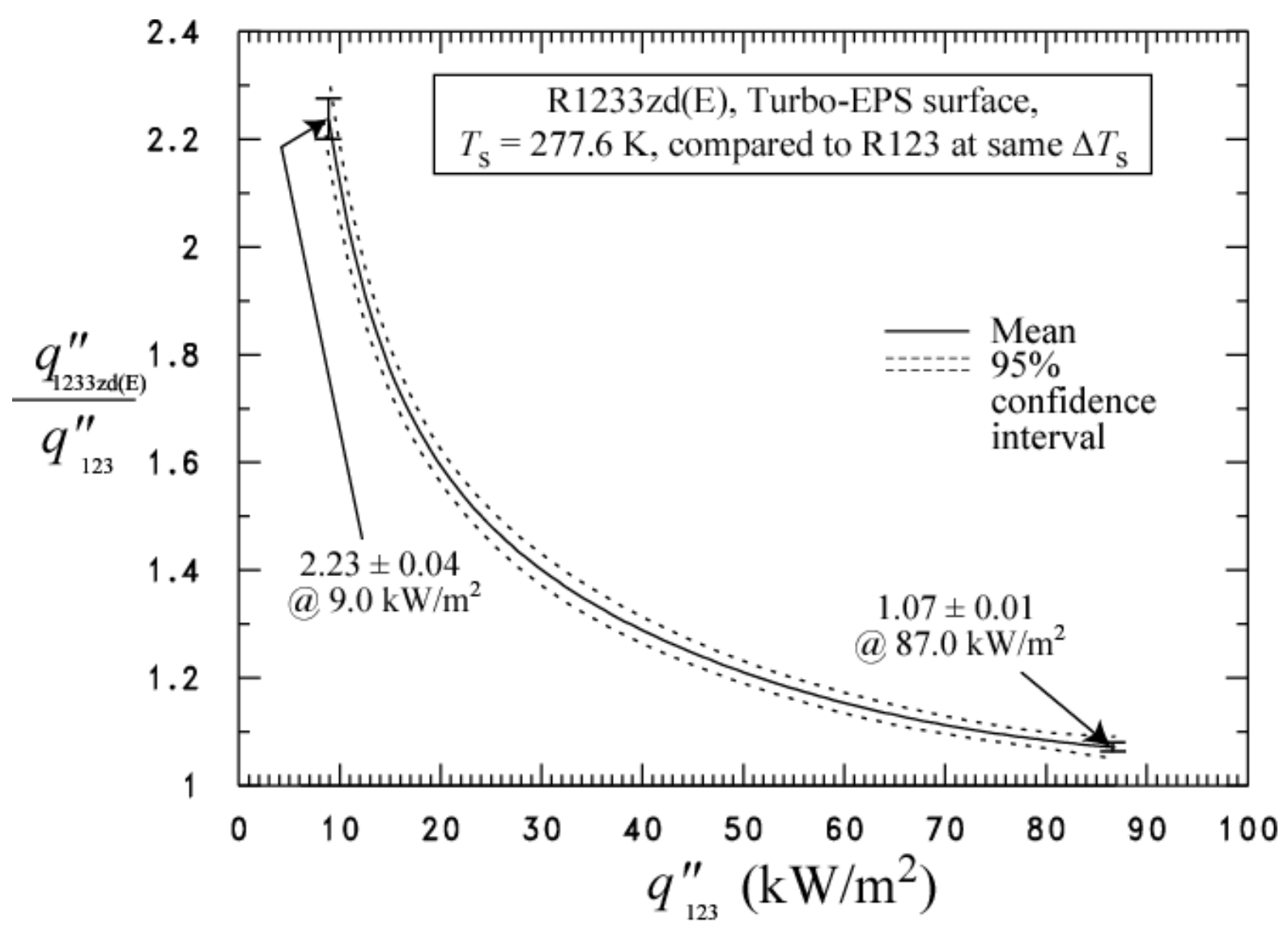

Fig. 7 Comparison of R1233zd(E) heat fluxes to that for R123 at the same wall superheat 


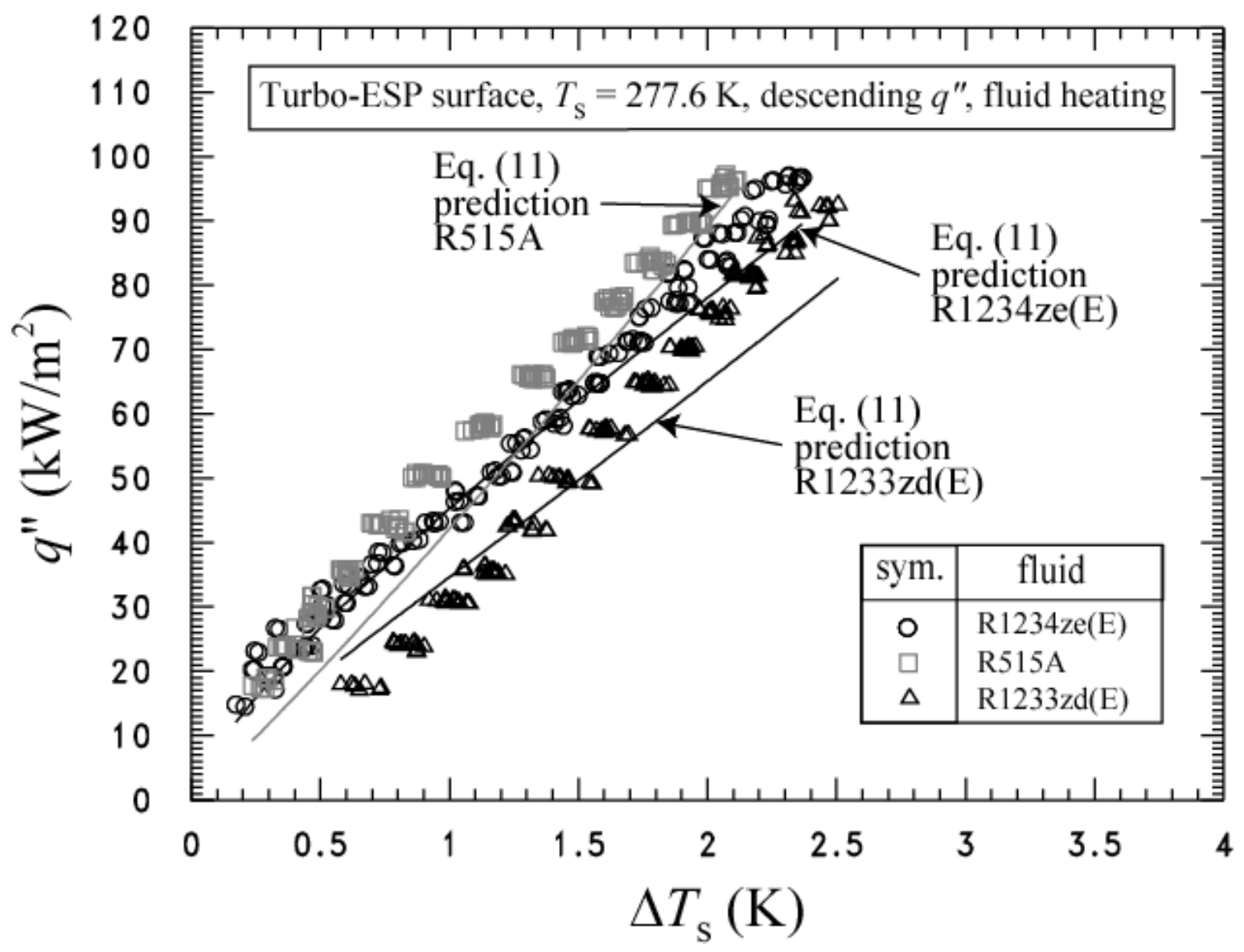

Fig. 8 Comparison of pool boiling model for Turbo-ESP surface to present measurements for R1234ze(E), R515A, and R1233zd(E) 


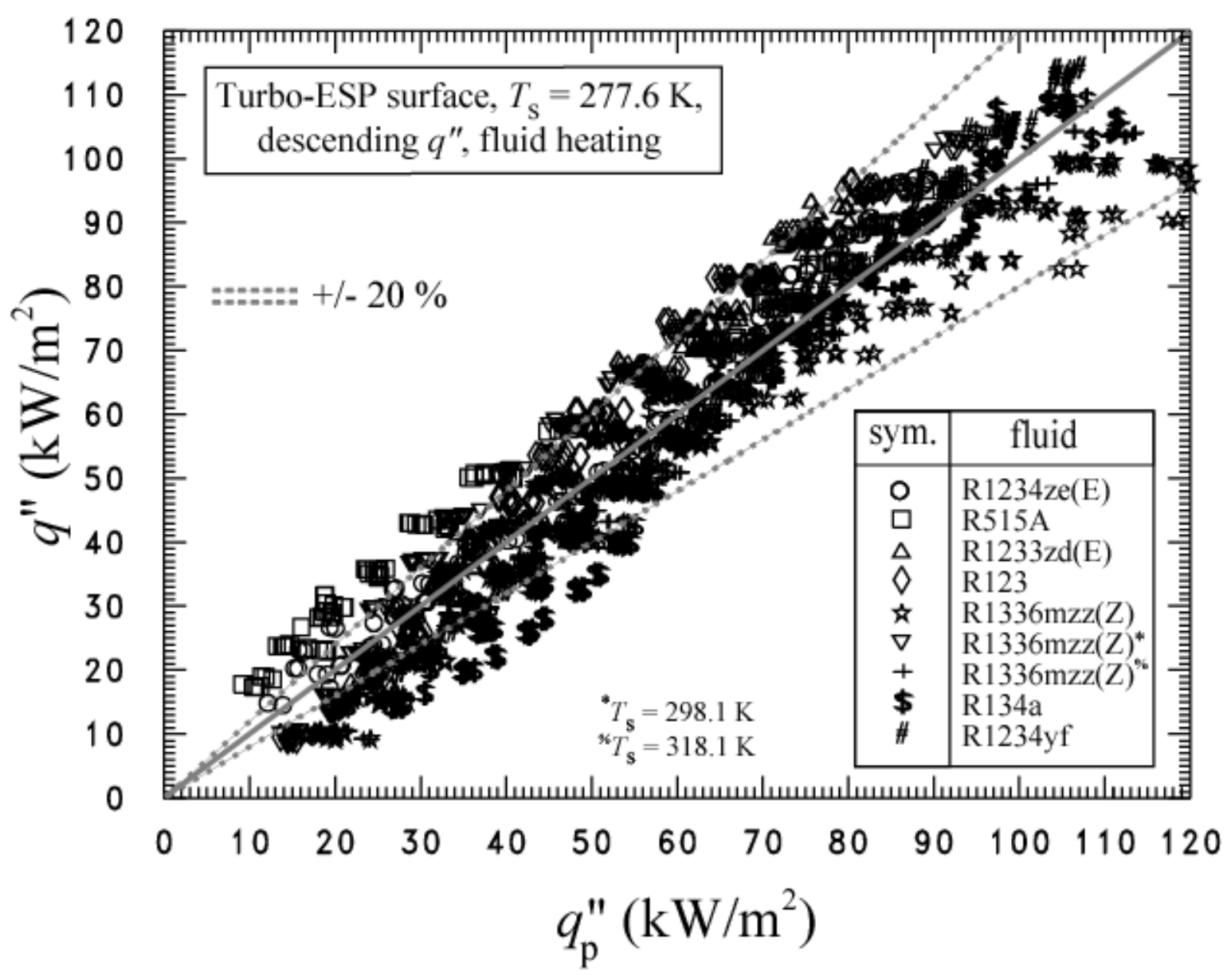

Fig. 9 Comparison of pool boiling model for Turbo-ESP surface to several refrigerants for several studies 


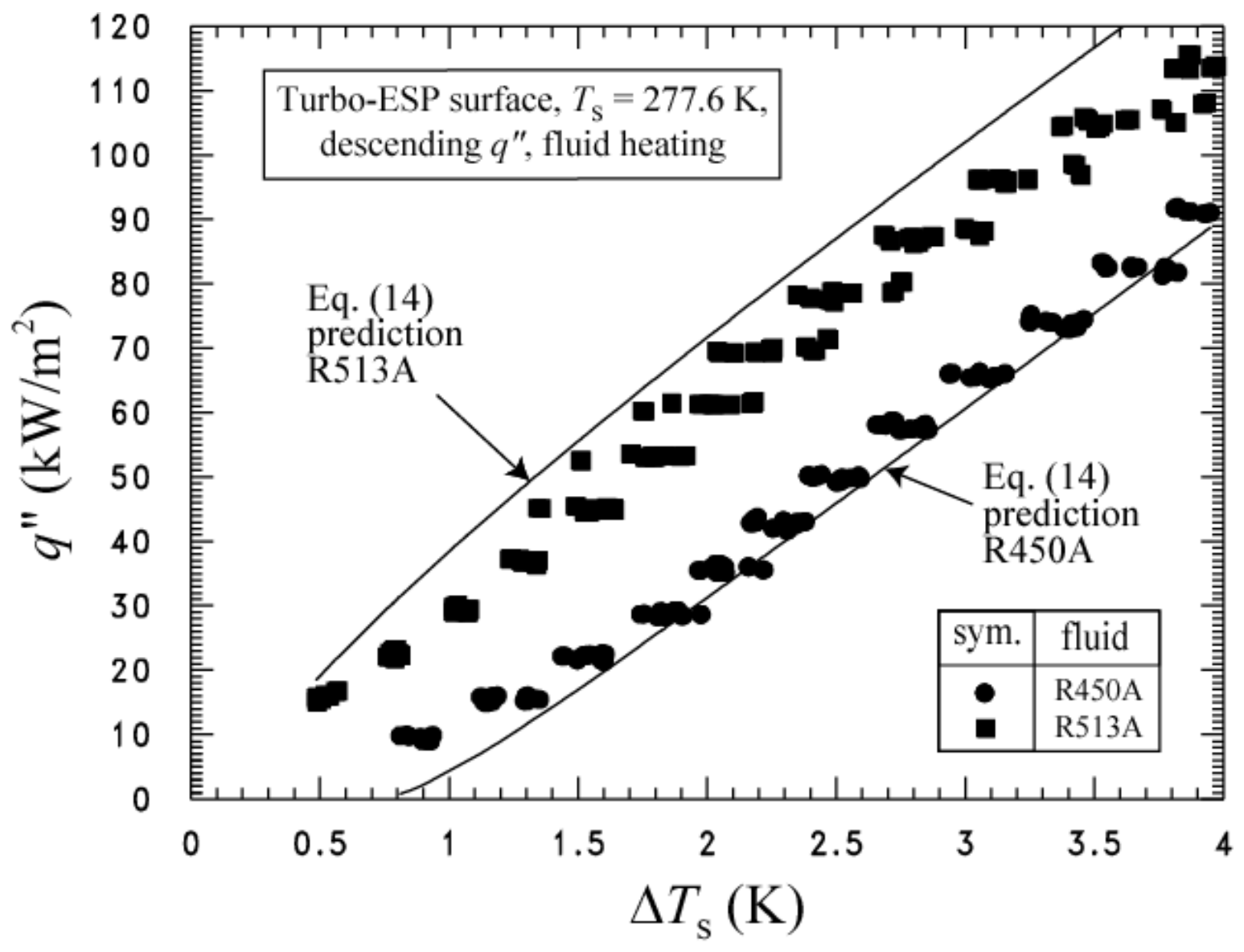

Fig. 10 Comparison of refrigerant mixture pool boiling model for Turbo-ESP surface to R450A and R513A measurements from Kedzierski et al. (2018) 


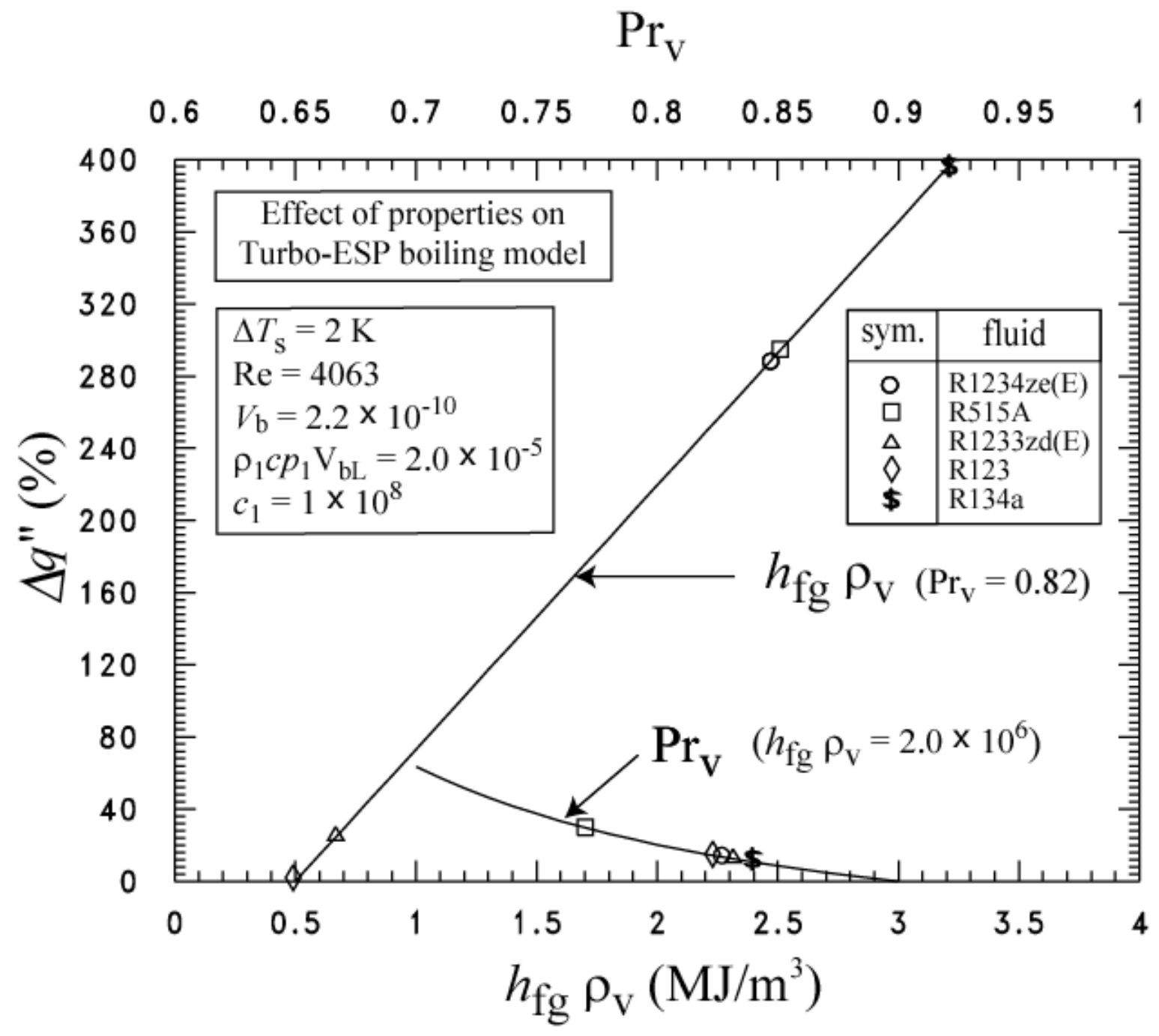

Fig. 11 Illustration of effect of key properties on pool boiling model heat flux 


\section{APPENDIX A: UNCERTAINTIES}

Figure A.1 shows the expanded relative (percent) uncertainty of the heat flux $\left(U_{\mathrm{q}}\right)$ as a function of the heat flux. Figure A.2 shows the expanded uncertainty of the wall temperature as a function of the heat flux. The uncertainties shown in Figs. A.1 and A.2 are "within-run uncertainties." These do not include the uncertainties due to "between-run effects" or differences observed between tests taken on different days. The "within-run uncertainties" include only the random effects and uncertainties associated with one particular test. All other uncertainties reported in this study are "between-run uncertainties" which include all random effects such as surface past history or seeding.

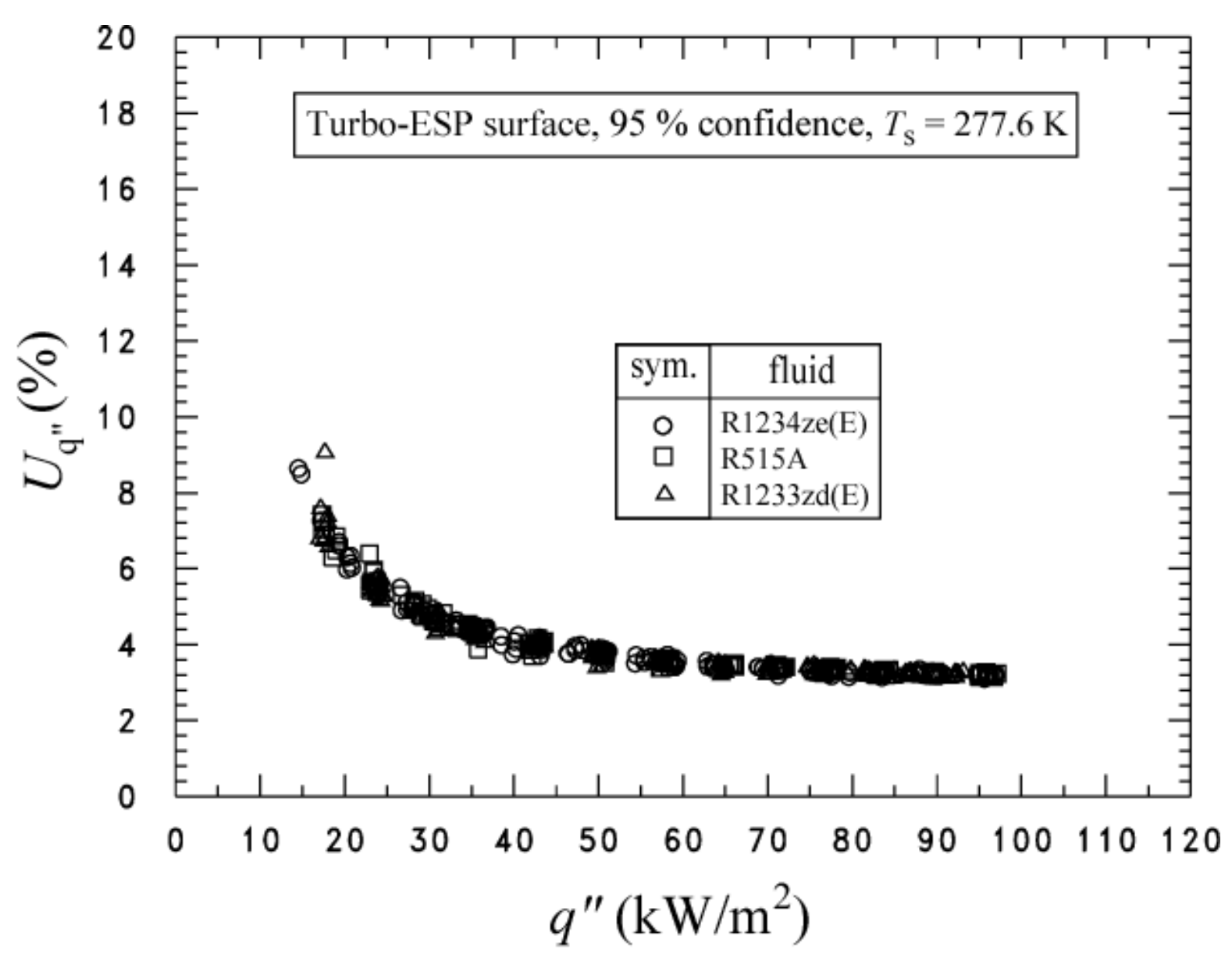

Fig. A.1 Expanded relative uncertainty in the heat flux of the surface at the $95 \%$ confidence level 


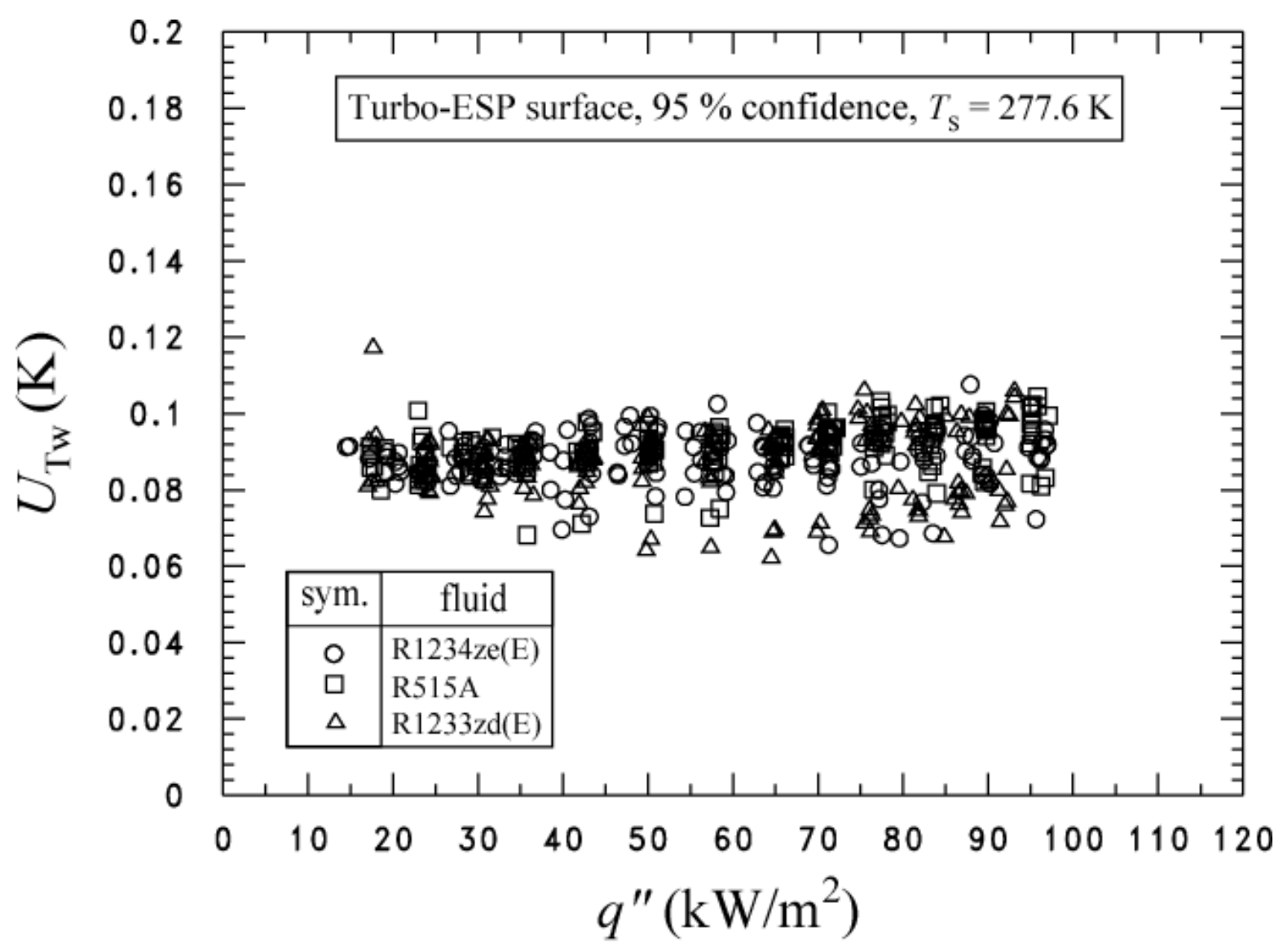

Fig. A.2 Expanded uncertainty in the temperature of the surface at the $95 \%$ confidence level 